FACULDADE DE ZOOTECNIA E ENGENHARIA DE ALIMENTOS

\title{
ALINE ZAMPAR
}

Comparação de estimativas de diferenças esperadas de progênie por três metodologias em touros da raça Nelore 


\section{ALINE ZAMPAR}

Comparação de estimativas de diferenças esperadas de progênie por três metodologias em touros da raça Nelore

Dissertação apresentada à Faculdade de Zootecnia e Engenharia de Alimentos da USP, como parte dos requisitos para a obtenção do Título de Mestre em Zootecnia.

Área de Concentração: Qualidade e Produtividade Animal.

Orientador: Prof. Dr. José Bento Sterman Ferraz 


\section{FICHA CATALOGRÁFICA}

preparada pela

Biblioteca da Faculdade de Zootecnia e Engenharia de Alimentos da Universidade de São Paulo

Zampar, Aline

Z26c Comparação de estimativas de diferenças esperadas de progênie por três metodologias em touros da raça Nelore. / Aline Zampar - Pirassununga, 2007.

$64 \mathrm{f}$.

Dissertação (Mestrado) - Faculdade de Zootecnia e Engenharia de Alimentos - Universidade de São Paulo.

Departamento de Ciências Básicas.

Área de Concentração: Qualidade e Produtividade Animal.

Orientador: José Bento Sterman Ferraz. 


\section{DEDICATÓRIA}

“Os estabelecimentos de ensino, propriamente do mundo, podem instruir, mas só o instituto da família pode educar. É por essa razão que a universidade poderá fazer o cidadão, mas somente o lar pode edificar o homem."

Emmanuel

Aos meus pais, Euclydes e Menilce, pelo carinho, compreensão, confiança e estímulo à realização desse trabalho.

Ao meu irmão Claudinei, pela amizade, entusiasmo e palavras de incentivo em todos os momentos. 


\section{AGRADECIMENTOS}

Ao grande Criador, pelas oportunidades concedidas, pela força doada, pela resignação e compreensão proporcionadas em todos os momentos. Ao meu mentor, pela proteção, por aclarar meus caminhos e fazer com que eu o percorra da maneira mais virtuosa possível.

Ao Prof. Dr. José Bento Sterman Ferraz, pela oportunidade, orientação, ensinamentos e formação de espírito crítico.

Ao Prof. Dr. Gerson Barreto Mourão (meu guru científico), pela imensa contribuição no desenvolvimento desse trabalho, pelo estímulo, conversas, conselhos, acolhida, pelo exemplo de vida. À sua esposa, Luciana, e seu filho, Gabriel, pela compreensão e receptividade.

Ao Prof. Dr. Júlio Cesar de Carvalho Balieiro, pelo apoio, incentivo e idéias, pela contribuição na minha formação, pelas prosas e risadas, pelo convívio, pelas experiências divididas.

Ao Prof. Dr. César Gonçalves de Lima, pela confiança depositada, pelos ensinamentos, pelas conversas e risadas, pelo apoio.

Ao Prof. Dr. Joanir Pereira Eler, pelos ensinamentos, apoio e conversas diversas.

Ao Dr. Luiz Alberto Fries e Dr. Roberto Carvalheiro pela abertura da metodologia e pelas contribuições na realização desse trabalho.

À equipe do Grupo de Melhoramento Animal (aos que passaram e aos que ainda permanecem), pela amizade, companheirismo, auxílio, conhecimentos compartilhados, trabalhos e também churrascos, festas, happy hours... de tudo isso sentirei saudade!

Aos amigos de pós-graduação, pela amizade e companheirismo. Aulas, conversas, discussões, JIZ, churrascos... tudo ficará registrado na lembrança!

A todos os amigos conquistados durante a graduação, em especial aos da XXII Turma de Zootecnia, turma com a qual convivi diariamente por pelo menos quatro anos.

Aos amigos da XXV Turma de Zootecnia, a qual me acolheu com muito carinho e que para sempre será lembrada com grande afeição.

Às meninas da “reps" e do "alojas”, pelo convívio, amizade, confidências, conversas, respeito e incentivo.

Aos amigos de São Carlos e demais localidades, aos meus familiares, pela força, compreensão da ausência e imenso carinho, por escutar meus desabafos e pelo incentivo em toda a jornada.

Ao Grupo Socorrista Joanna de Ângelis, pelos ensinamentos, exemplos de vida e sabedoria, pelos momentos de alegria e suporte espiritual.

Aos amigos que não mais estão nesse plano, mas que tenho certeza que olham por mim.

A todos os professores e funcionários da querida FZEA pela dedicação e contribuição para que haja um ensino de qualidade. 


\section{EPÍGRAFE}

“Comece fazendo o que é necessário, depois o que é possível, e de repente você estará fazendo o impossível."

São Francisco de Assis

"Sejamos nós mesmos as mudanças que queremos ver no mundo." Mahatma Gandhi

“O aprendizado é ação. Do contrário, é só informação.” 


\section{RESUMO}

\section{ZAMPAR, A. Comparação de estimativas de diferenças esperadas de progênie por três}

metodologias em touros da raça Nelore. 2007. 64f. Dissertação (Mestrado) - Faculdade de Zootecnia e Engenharia de Alimentos, Universidade de São Paulo, Pirassununga, 2007.

A tendência atual, imposta pela competitividade do mercado, exige bovinos mais eficientes e adequados ao sistema de produção, visando atender a demanda pela qualidade de carne. Em função disso, o melhoramento genético vem sendo utilizado, de forma a incrementar a eficiência dos rebanhos, proporcionando assim, maior rentabilidade ao sistema. Assim, o presente estudo foi conduzido com o propósito de estudar a variabilidade da progênie de touros submetidos à avaliação genética, através da análise das Diferenças Esperadas na Progênie (DEP) dos filhos de 359 reprodutores. As DEP das progênies foram estimadas por procedimentos REML e as avaliações de touros por metodologias alternativas, foram realizadas com o auxílio do software SAS. Foram utilizados 45.014 dados de peso à desmama (PD), 45.014 de peso ao sobreano (PS) e 45.014 de ganho de peso da desmama ao sobreano (GP) de bovinos de corte da raça Nelore, criados em uma fazenda em região tropical do Brasil. As DEPs dos touros foram estimadas de acordo com três métodos: uso da média aritmética, média harmônica acrescida da média da característica estudada e média harmônica simples. Os resultados sugerem que o uso da média harmônica na estimação de DEPs com o objetivo de ajustar o valor genético aditivo de um touro para a dispersão dos valores genéticos de suas progênies não trouxe diferenças importantes em relação à estimativa pela média aritmética, na população estudada. No entanto, dadas as implicações e importância de novas metodologias, são necessários maiores estudos em busca de se encontrar uma metodologia que permita maior uniformidade das progênies de touros.

Palavras-chave: bovinos de corte; variabilidade; progênie, média harmônica, DEP, CEIP. 


\begin{abstract}
ZAMPAR, A. Comparison of expected progeny difference estimatives by three methodologies in Nellore beef cattle. 2007. 64p. M. Sc. Dissertation - Faculdade de Zootecnia e Engenharia de Alimentos, Universidade de São Paulo, Pirassununga, 2007.
\end{abstract}

The strong competition in beef market imposed an actual trend of searching for quality in beef production systems, trying to attend the consumers' demand. Due to the necessity of increasing productivity, animal breeding programs have been utilized to increase cattle efficiency, offering more profitability to the production system. The present study was carried out to contribute to knowledge about sires' progeny variability, using Expected Progeny Difference (EPD) from calves of 359 sires. EPD’s were estimated by REML procedures. The prediction od bull's EPD's were performed by software SAS, using 45,014 data of weaning weight (PD), 45,014 of post-weaning weight (PS) and 45,014 of weight gain post-weaning (GP) from Nellore beef cattle, raised in a tropical area of Brazil. Those data were analyzed according with three methods: application of arithmetic mean, harmonic mean of EPD added by trait mean and only harmonic mean. Results suggested that estimation of EPDs using harmonic mean on condition that adjust sire's additive genetic value to dispersion form its calves' genetic values did not make difference to the prediction trough arithmetic mean in the population studied. Due to the implications and importance of alternative methods to adjust bull's EPDs to variability of progeny, further studies are necessary to search for better progeny’s uniformity.

Keywords: beef cattle; variability; progeny, harmonic mean, EPD, CEIP. 


\section{LISTA DE FIGURAS}

Figura 1 - Curvas de distribuição de dados populacionais simétricos e assimétricos.............24

Figura 2 - Curvas de distribuição de populações de acordo com o coeficiente de curtose......24

Figura 3 - Curva da distribuição normal de probabilidade .................................................. 25

Figura 4 - Dispersões das DEPs para peso à desmama nos quadrantes definidos pelos pontos de truncamentos dos 10\% melhores touros para os modelos HK (DEPhk $\geq 190,36$ $\mathrm{kg})$ e $\mathrm{M}(\mathrm{DEPm} \geq 9,40 \mathrm{~kg})$

Figura 5 - Dispersões das DEPs para peso à desmama nos quadrantes definidos pelos pontos de truncamentos dos 25\% melhores touros para os modelos HK (DEPhk $\geq 189,26$ $\mathrm{kg})$ e $\mathrm{M}(\mathrm{DEPm} \geq 8,30 \mathrm{~kg})$ 36

Figura 6 - Dispersões das DEPs para peso à desmama nos quadrantes definidos pelos pontos de truncamentos dos 50\% melhores touros para os modelos HK (DEPhk $\geq 187,33$ $\mathrm{kg})$ e $\mathrm{M}(\mathrm{DEPm} \geq 6,87 \mathrm{~kg})$ 37

Figura 7 - Dispersões das DEPs para peso à desmama nos quadrantes definidos pelos pontos de truncamentos dos 10\% melhores touros para os modelos HS (DEPhs $\geq 9,60 \mathrm{~kg}$ ) e $M(D E P m \geq 9,40 \mathrm{~kg})$.

Figura 8 - Dispersões das DEPs para peso à desmama nos quadrantes definidos pelos pontos de truncamentos dos 25\% melhores touros para os modelos HS (DEPhs $\geq 7,88 \mathrm{~kg}$ ) e $\mathrm{M}(\mathrm{DEPm} \geq 8,30 \mathrm{~kg})$

Figura 9 - Dispersões das DEPs para peso à desmama nos quadrantes definidos pelos pontos de truncamentos dos 50\% melhores touros para os modelos HS (DEPhs $\geq 5,85 \mathrm{~kg}$ ) e $M(D E P m \geq 6,37 \mathrm{~kg})$

Figura 10 - Dispersões das DEPs para peso ao sobreano nos quadrantes definidos pelos pontos de truncamentos dos 10\% melhores touros para os modelos $\mathrm{HK}$ (DEPhk $\geq$ $321,5 \mathrm{~kg})$ e $\mathrm{M}(\mathrm{DEPm} \geq 17,56 \mathrm{~kg})$ 44

Figura 11 - Dispersões das DEPs para peso ao sobreano nos quadrantes definidos pelos pontos de truncamentos dos 25\% melhores touros para os modelos HK (DEPhk $\geq$ $318,48 \mathrm{~kg})$ e $M(D E P m \geq 14,52 \mathrm{~kg})$

Figura 12 - Dispersões das DEPs para peso ao sobreano nos quadrantes definidos pelos pontos de truncamentos dos 50\% melhores touros para os modelos HK (DEPhk $\geq$ $314,62 \mathrm{~kg})$ e $\mathrm{M}(\mathrm{DEPm} \geq 10,71 \mathrm{~kg})$

Figura 13 - Dispersões das DEPs para peso ao sobreano nos quadrantes definidos pelos pontos de truncamentos dos 10\% melhores touros para os modelos HS (DEPhs $\geq$ 
$17,76 \mathrm{~kg})$ e $\mathrm{M}(\mathrm{DEPm} \geq 17,55 \mathrm{~kg})$.

Figura 14 - Dispersões das DEPs para peso ao sobreano nos quadrantes definidos pelos pontos de truncamentos dos 25\% melhores touros para os modelos HS (DEPhs $\geq$

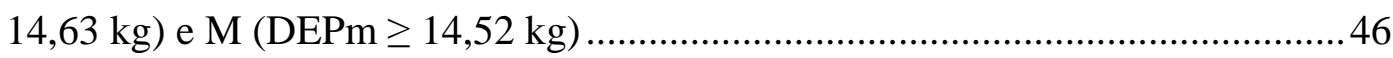

Figura 15 - Dispersões das DEPs para peso ao sobreano nos quadrantes definidos pelos pontos de truncamentos dos 50\% melhores touros para os modelos HS (DEPhs $\geq$ $10,26 \mathrm{~kg})$ e $\mathrm{M}(\mathrm{DEPm} \geq 10,71 \mathrm{~kg})$ 47

Figura 16 - Dispersões das DEPs para ganho de peso da desmama ao sobreano nos quadrantes definidos pelos pontos de truncamentos dos $10 \%$ melhores touros para os modelos HK (DEPhk $\geq 123,53 \mathrm{~kg})$ e $\mathrm{M}(\mathrm{DEPm} \geq 8,60 \mathrm{~kg})$ 51

Figura 17 - Dispersões das DEPs para ganho de peso da desmama ao sobreano nos quadrantes definidos pelos pontos de truncamentos dos 25\% melhores touros para os modelos HK (DEPhk $\geq 121,42 \mathrm{~kg})$ e $\mathrm{M}(\mathrm{DEPm} \geq 6,49 \mathrm{~kg})$ 51

Figura 18 - Dispersões das DEPs para ganho de peso da desmama ao sobreano nos quadrantes definidos pelos pontos de truncamentos dos 50\% melhores touros para os modelos HK (DEPhk $\geq 118,99 \mathrm{~kg})$ e M (DEPm $\geq 4,05 \mathrm{~kg})$. 52

Figura 19 - Dispersões das DEPs para ganho de peso da desmama ao sobreano nos quadrantes definidos pelos pontos de truncamentos dos $10 \%$ melhores touros para os modelos HS (DEPhs $\geq 10,26 \mathrm{~kg})$ e $\mathrm{M}(\mathrm{DEPm} \geq 8,60 \mathrm{~kg})$. 55

Figura 20 - Dispersões das DEPs para peso ao sobreano nos quadrantes definidos pelos pontos de truncamentos dos 25\% melhores touros para os modelos HS (DEPhs $\geq$ $7,29 \mathrm{~kg})$ e $M(\mathrm{DEPm} \geq 6,49 \mathrm{~kg})$ 55

Figura 21 - Dispersões das DEPs para peso ao sobreano nos quadrantes definidos pelos pontos de truncamentos dos 50\% melhores touros para os modelos HS (DEPhs $\geq$

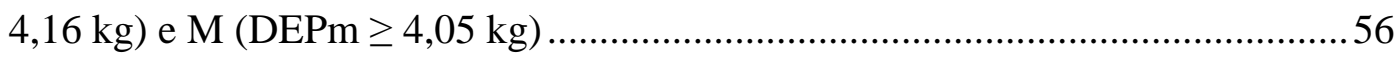




\section{LISTA DE TABELAS}

Tabela 1 - Rebanho de bovinos de corte e produção de carne no Brasil .................................. 14

Tabela 2 - Evolução das exportações brasileiras de carne bovina* ........................................15

Tabela 3 - Freqüência absoluta de informações para as características no banco de dados.... 29

Tabela 4 - Número de observações (n), média, desvio-padrão (dp), coeficiente de variação (cv), mínimo (min) e máximo (max) das características analisadas.

Tabela 5 - Estatística descritiva das metodologias de estimação de dep para peso à desmama: média, desvio-padrão (dp), mínimo (min) e máximo (max)

Tabela 6 - Comparação entre as metodologias hs e m, para os touros discordantes do topo da classificação para a característica peso à desmama................................................. 34

Tabela 7 - Média das acurácias dos touros discordantes e selecionados por cada um dos métodos para peso a desmama ..............................................................................36

Tabela 8 - Comparação entre as metodologias hs e m, para os touros discordantes do final da classificação para a característica peso a desmama

Tabela 9 - Taxa de discordância (\%) entre os touros das metodologias hs e m para peso a

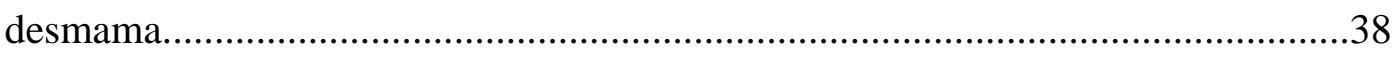

Tabela 10 - Correlações simples e de rank das deps dos touros obtidas a partir dos diferentes modelos hs, hk e m, para peso a desmama

Tabela 11 - Estatística descritiva das metodologias de estimação de dep para peso ao sobreano: média, desvio-padrão (dp), mínimo (min) e máximo (max).

Tabela 12 - Comparação entre as metodologias hs e m, para os touros discordantes do topo da classificação para a característica peso ao sobreano

Tabela 13 - Comparação entre as metodologias hk e m, para os touros discordantes do topo da classificação para a característica peso ao sobreano

Tabela 14 - Média das acurácias dos touros discordantes e selecionados por cada um dos métodos para peso ao sobreano

Tabela 15 - Taxa de discordância (\%) entre os touros das metodologias hs e hk em comparação com m para peso ao sobreano

Tabela 16 - Comparação entre as metodologias hs e m, para os touros do final da classificação para a característica peso ao sobreano

Tabela 17 - Comparação entre as metodologias hk e m, para os touros discordantes do final da classificação para a característica peso ao sobreano 
Tabela 18 - Taxa de discordância (\%) entre os touros das metodologias hk e hs em comparação com m, para peso ao sobreano..........................................................49

Tabela 19 - Correlações simples e de rank das deps dos touros obtidas a partir dos diferentes modelos hs, hk e m, para peso ao sobreano. 49

Tabela 20 - Estatística descritiva das metodologias de estimação de dep para ganho de peso da desmama ao sobreano: média, desvio-padrão (dp), mínimo (min) e máximo (max) .50

Tabela 21 - Comparação entre as metodologias hs e m, para os touros discordantes do topo da classificação para a característica ganho de peso da desmama ao sobreano............53

Tabela 22 - Média das acurácias dos touros discordantes e selecionados por cada um dos métodos para ganho de peso da desmama ao sobreano.

Tabela 23 - Comparação entre as metodologias hs e m, para os touros discordantes do final da classificação para a característica ganho de peso da desmama ao sobreano 54

Tabela 24 - Taxa de discordância (\%) entre os touros das metodologias hs e m para ganho de peso da desmama ao sobreano. 54

Tabela 25 - Correlações simples e de rank das deps dos touros obtidas a partir dos diferentes modelos hs, hk e m, para ganho de peso da desmama ao sobreano .56 


\section{SUMÁRIO}

1. INTRODUÇÃ

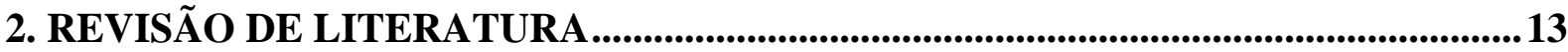

2.1. PRODUÇÃO E MERCADO DA CARNE BOVINA NO BRASIL .............................................. 13

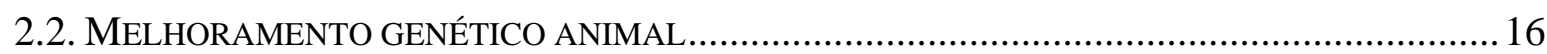

2.3. CARACTERÍSTICAS ESTUDADAS NOS PROGRAMAS DE MELHORAMENTO GENÉTICO DE

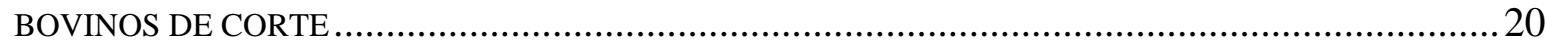

2.4. CEIP (CERTIFICADO ESPECIAL DE IDENTIFICAÇÃO E PRODUÇÃO) .................................. 21

2.5. ESTATÍSTICAS DESCRITIVAS - MEDIDAS DE TENDÊNCIA CENTRAL E DE DISPERSÃO.......... 22

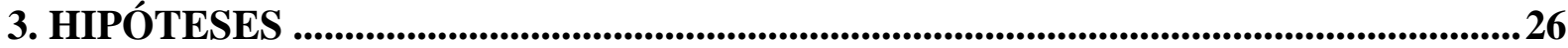

4. OBJETIVOS ............................................................................................................................ 27

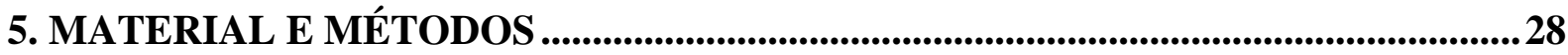

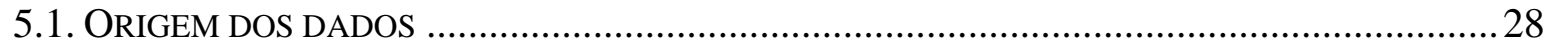

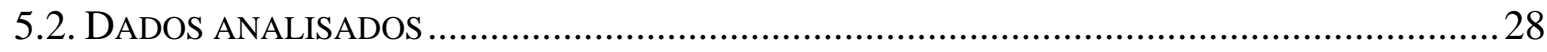

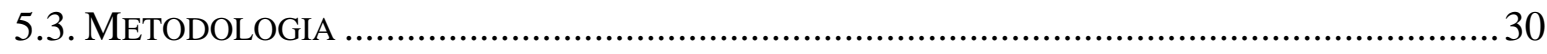

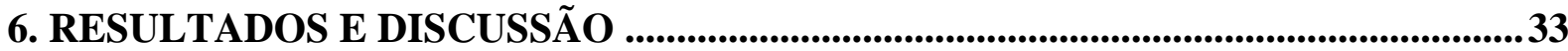

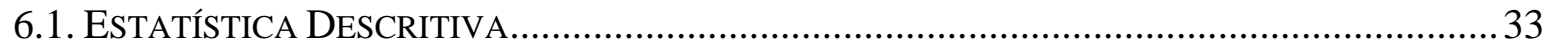

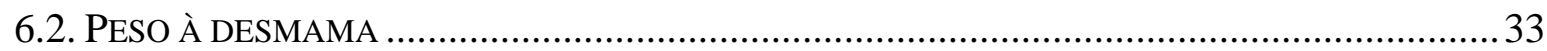

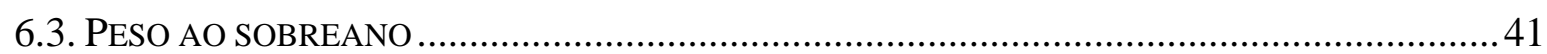

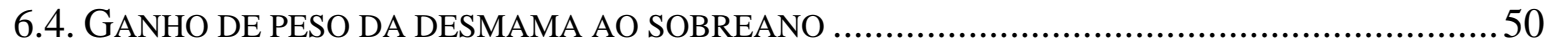

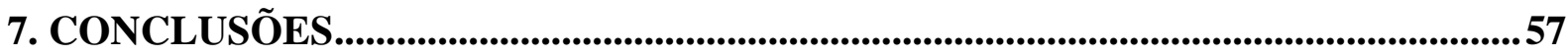

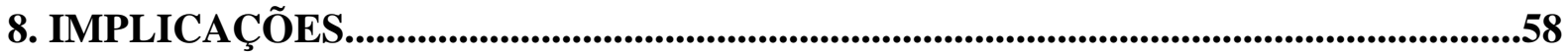

9. REFERÊNCIAS BIBLIOGRÁFICAS .........................................................................59 


\section{INTRODUÇÃO}

O Brasil é um dos maiores produtores mundiais de bovinos de corte, sendo que, em sua maioria, os animais são de raças zebuínas e criados em sistema extensivo de produção. A raça Nelore é a principal raça criada no país, devido à alta capacidade de adaptação ao clima tropical, destacando-se a resistência aos endo e ectoparasitos, a tolerância às altas temperaturas e sua sobrevivência sob condições de manejo e alimentação adversas.

A pecuária nacional, pela sua dimensão, permite a exploração de uma ampla variedade de recursos genéticos, em diversos tipos de ambiente. Porém, melhorar a eficiência da bovinocultura brasileira é condição básica para aumentar a competitividade do setor no mercado e com isso, alavancar a capacidade de resposta econômica aos investimentos realizados, pois embora o cenário seja bastante promissor, os índices zootécnicos ainda se encontram aquém do potencial que essa cultura possui.

Nesse sentido, criadores vêm procurando empregar novas tecnologias para otimizar os ganhos e eficiência dos rebanhos. Dentre as alternativas disponíveis, a utilização de técnicas de melhoramento genético animal pode contribuir para tornar a pecuária de corte competitiva e atraente. O aumento da produtividade pode ser obtido a partir da identificação e multiplicação dos melhores genótipos e da adequação das condições ambientais relacionadas ao processo produtivo. Desse modo, a seleção, umas das ferramentas do melhoramento genético animal, pode ser usada para modificar a constituição genética de uma população, o que ocorre devido à alteração das freqüências dos alelos que determinam a expressão das características de interesse, por meio de uma reprodução assistida com animais de desempenho superior comprovado.

Porém, em avaliações genéticas, mesmo sendo “superiores”, ou seja, tendo predições de valor genético aditivo melhores, reprodutores selecionados podem apresentar grande variabilidade em sua progênie, uma vez que há outros fatores que interferem na expressão dos genes.

Assim, foi proposta a idéia de estudar a variabilidade da progênie dos touros, utilizando-se das diferenças esperadas na progênie (DEPs), procurando penalizar os reprodutores que apresentassem progênie muito dispersa, empregando então, ao invés da média aritmética, a média harmônica na estimação das a qual é calculada a partir da divisão do número de filhos do touro pelo inverso do somatório das DEPs dos filhos na característica estudada. Para que essa hipótese seja validada, um estudo mais detalhado da distribuição 
dessa progênie pode ser útil, valendo-se dos coeficientes de curtose e assimetria e de outras ferramentas associadas às estatísticas descritivas e inferências.

Nesse contexto, a diferença esperada na progênie (DEP), um valor que representa uma estimativa do mérito genético médio das informações contidas nos gametas de determinado indivíduo para uma característica particular, passou a ser expressa também através da média harmônica dos valores genéticos da progênie de um reprodutor. Essa estimativa poderia ser utilizada para se comparar reprodutores que foram submetidos à avaliação genética e com isso tomar a decisão sobre a utilização de um ou outro reprodutor em um determinado rebanho.

Desse modo, o objetivo do presente estudo foi estimar a diferença esperada na progênie (DEP) de touros, utilizando-se dos seguintes critérios: média aritmética das DEPs dos filhos e média harmônica das DEPs dos filhos acrescida da média da característica estudada e média harmônica simples das DEPs dos filhos de touros, em um rebanho da raça Nelore, visando comparar essas metodologias de estimação, bem como, avaliar a viabilidade da utilização da DEP harmônica na expressão dos valores genéticos aditivos de reprodutores, ajustados para a variabilidade da progênie, em relação a metodologia tradicional de obtenção da DEP.

\section{REVISÃO DE LITERATURA}

\subsection{Produção e mercado da carne bovina no Brasil}

A pecuária de corte está presente no panorama econômico nacional desde a época da colonização. Nos três primeiros séculos após o descobrimento do Brasil, os animais domésticos tinham por finalidade o trabalho, alimentação e agasalho e eram criados de forma extrativista e empírica. A criação orientada para produção com intuito comercial só teve início no princípio do século XIX, a partir das primeiras importações do gado bovino da Índia (EUCLIDES FILHO, 1999).

Nas décadas mais recentes, com a expansão agrícola e incorporação de novas terras, ocorreu um maior desenvolvimento da atividade. A pecuária de corte está presente em todo o território nacional, porém, a região Centro-Sul é a que detém a concentração do rebanho, destacando-se os Estados de Mato Grosso, Mato Grosso do Sul, Minas Gerais e Goiás, que juntos representam mais de 45\% do rebanho nacional (IBGE, 2005).

A produção sempre foi caracterizada pelo sistema extensivo, devido à vasta extensão 
territorial. Porém, nos últimos anos, com a inclusão de novas tecnologias em busca de maior produtividade, houve aumento do número de confinamentos e semi-confinamentos, sistemas intensivos de produção, aumentando conseqüentemente a produção de carne bovina. Nos últimos 13 anos, a produção teve um incremento de mais de $70 \%$, como pode ser visualizado na Tabela 1.

Tabela 1 - Rebanho de bovinos de corte e produção de carne no Brasil

\begin{tabular}{ccc}
\hline Ano & $\begin{array}{c}\text { Rebanho } \\
\text { (milhões de cabeças) }\end{array}$ & $\begin{array}{c}\text { Produção de carne } \\
\text { (mil toneladas }{ }^{\mathbf{~}}\end{array}$ \\
\hline 1994 & 158,2 & 5.200 \\
1995 & 155,9 & 5.400 \\
1996 & 153,1 & 6.045 \\
1997 & 156,1 & 5.820 \\
1998 & 157,8 & 6.040 \\
1999 & 159,2 & 6.270 \\
2000 & 164,3 & 6.650 \\
2001 & 170,6 & 6.900 \\
2002 & 179,2 & 7.300 \\
2003 & 189,1 & 7.700 \\
2004 & 192,5 & 8.350 \\
2005 & 195,5 & 8.750 \\
2006 & 198,5 & 9.020 \\
2007 (abr) & - & 9.325 \\
\hline
\end{tabular}

Adaptado de USDA e ABIEC

Nota: ${ }^{1}$ - Equivalente carcaça.

A importância da cadeia de carne bovina brasileira no mercado internacional é evidente e sua intensidade tem crescido fortemente, principalmente a partir do final da década de 90, quando ocorreu a profissionalização da atividade, através do controle sanitário, preocupação com baixo custo e melhor qualidade do produto final. Com a crescente produção de carne, o país assumiu no fim de 2003, o posto de maior exportador mundial de carne bovina, embora o maior produtor seja os Estados Unidos. Isso acontece porque apesar de ser o maior produtor, a população estadosunidense é a que mais consome também (ABIEC, 2007; CARVALHO, 2007). A evolução das exportações brasileiras de carne bovina está mais bem 
detalhada na Tabela 2.

Tabela 2 - Evolução das exportações brasileiras de carne bovina*

\begin{tabular}{cccc}
\hline Ano & $\begin{array}{c}\text { In Natura } \\
\text { (1000 toneladas) }\end{array}$ & $\begin{array}{c}\text { Industrializada } \\
\text { (1000 toneladas) }\end{array}$ & $\begin{array}{c}\text { Total } \\
\text { (1000 toneladas) }\end{array}$ \\
\hline 1990 & 100 & 149 & 249 \\
1991 & 74 & 252 & 326 \\
1992 & 124 & 320 & 444 \\
1993 & 102 & 290 & 392 \\
1994 & 88 & 270 & 358 \\
1995 & 44 & 225 & 269 \\
1996 & 52 & 209 & 261 \\
1997 & 70 & 204 & 274 \\
1998 & 109 & 234 & 343 \\
1999 & 170 & 292 & 462 \\
2000 & 210 & 245 & 455 \\
2001 & 460 & 172 & 632 \\
2002 & 529 & 204 & 733 \\
2003 & 819 & 235 & 1.054 \\
2004 & 1.100 & 286 & 1.386 \\
2005 & 1.235 & 375 & 1.610 \\
2006 & 1.334 & 396 & 1.730 \\
\hline
\end{tabular}

Fonte: ABIEC - Associação Brasileira das Indústrias Exportadoras de Carne (2007)

* Associados da ABIEC.

De acordo com a ABIEC (2007), o rebanho brasileiro de bovinos de corte corresponde a $20 \%$ do total mundial, e da produção correspondente a $16 \%$. Devido a diversos fatores, a exportação brasileira de carne bovina corresponde, atualmente, a 31\% do total exportado no mercado mundial, ou seja, a cada três quilos de carne comercializada no mundo, um quilo é de carne brasileira.

Apesar da grande expansão das exportações, o mercado interno não sofreu com as ofertas e preços da carne, uma vez que houve incremento da produção. Cerca de $80 \%$ da carne bovina produzida é destinada ao mercado interno. O consumo per capta de carne bovina também aumentou, principalmente depois da implantação do plano de estabilização da economia, o Plano Real, em 1994. Porém, a cadeia da carne bovina ainda enfrenta problemas de ordem social e econômica, em função das carnes substitutas apresentarem-se mais baratas 
(CARVALHO, 2007).

Com isso, o Brasil passou cada vez mais a se destacar no mercado mundial e atrair investidores internacionais, os quais inserem capital e novas tecnologias na atividade.

\subsection{Melhoramento genético animal}

Mudanças expressivas ocorreram nos programas de melhoramento animal de bovinos de corte no Brasil nas últimas décadas. O que era antes exercido apenas por alguns criadores, muitas vezes se utilizando a intuição, passou a ter embasamento científico e uso de tecnologias. Porém, para que um programa de melhoramento seja bem sucedido, é necessário que se faça de maneira competitiva, com o uso de tecnologias cabíveis (VAN DER WERF, 2006). Por isso, um dos desafios dos geneticistas é a definição de critérios de seleção que auxiliem na escolha de reprodutores que originem animais adequados ao sistema de produção, maximizem lucros, minimizem riscos e que atendam a demanda do mercado consumidor (MUNIZ, 2005). Assim, é preciso que se definam, com precisão, os objetivos e critérios de seleção, pois a escolha errônea de uma característica pode ser pior que não promover melhoramento algum. Segundo Garnero et al. (2002), o valor econômico de um animal reprodutor não é determinado por uma característica isolada, mas sim pelo conjunto de características, as quais quando avaliadas simultaneamente, apresentam maior valor econômico.

A produção animal resulta da ação conjunta de dois fatores: genético e ambiental. A parte genética é a base para o estabelecimento de programas de melhoramento e é o fator que limita a capacidade de resposta dos animais aos processos seletivos. Porém, é indispensável que se procure compatibilizar o fator genético com as condições ambientais disponíveis à exploração animal, uma vez que a atuação do selecionador ao valorizar indivíduos geneticamente superiores pode pôr em risco a perda do valor adaptativo do indivíduo (PEREIRA, 2004). Toda informação fenotípica deve ser pré-ajustada ou corrigida para fatores sistemáticos que podem influenciar o desempenho dos animais, como a influência da idade da mãe sobre pesos e ganhos de peso, principalmente na fase de pré-desmama, grupo de contemporâneos, idade à mensuração, dentre outros. (BERGMANN, 2004). A separação da fração genética daquela devido ao ambiente e a determinação da importância relativa dos efeitos aditivos genéticos diretos são necessárias quando se pretende formular planos de melhoramento animal (FERREIRA et al., 1999), principalmente na fase pós-desmama, quando esses efeitos têm grande influência na resposta animal. 
Alguns princípios são seguidos quando se trata de um programa de melhoramento. É comum pensar que fenótipos melhores devem provir de genótipos melhores, porém, deve-se levar em conta o ambiente em que o animal está inserido. Outro princípio é de que se genótipos melhores são utilizados como reprodutores, então esses genes serão transmitidos à sua progênie com uma maior freqüência e, conseqüentemente, as progênies terão genótipos melhores, quando comparadas com animais que não tem pais testados. Porém, a resposta esperada a um programa de seleção depende de alguns fatores, como: a superioridade dos pais selecionados em relação à média da população, da acurácia de seleção dos pais e de quanto de sua superioridade será transmitida à próxima geração, bem como, a velocidade com que as gerações são substituídas (VAN VLECK, 1993; VAN DER WERF, 2006; BIJMA, MUIR e VAN ARENDONK, 2007). Portanto, a correta identificação dos animais geneticamente superiores é determinante para o progresso genético da população. É de extrema importância o conhecimento sobre quanto das diferenças observadas nas características de interesse no melhoramento deve-se a fatores genéticos que serão transmissíveis às futuras progênies por meio de seleção (EVERLING et al., 2001), uma vez que o efeito básico da seleção é a alteração das freqüências gênicas (FALCONER, 1970), causando mudanças no fenótipo dos animais.

O desenvolvimento coerente de um programa de melhoramento começa com a definição dos seus objetivos. Em seguida, são atribuídas a essas características suas respectivas importâncias (OLSON et al., 2006). Na prática, muitas características estão envolvidas na determinação do mérito econômico. A questão é saber quando todas as características devem ser incluídas em um índice de seleção e quando limitar apenas àquelas mais importantes (SIVANADIAN \& SMITH, 1997), devendo-se estar atento à diferença desejada na mudança genética (KINGHORN, 2006; BIJMA; MUIR e VAN ARENDONK, 2007). Os valores econômicos têm sido considerados há algum tempo nos sistemas de produção de gado de corte, porém poucos resultados são diretamente comparáveis (BOURDON \& BRINKS, 1987; PONZONI \& NEWMAN, 1989; NEWMAN et al., 1992; KOOTS \& GIBSON, 1998). É importante determinar a sensibilidade dos valores econômicos para mudanças no mercado e circunstâncias de produção, para entender suas limitações, combinando produção e ambientes economicamente viáveis (KOOTS \& GIBSON, 1998). Além disso, Koots \& Gibson (1998) comentam que o valor econômico é mais sensível às mudanças no preço da alimentação do que às mudanças no preço da carne.

A herdabilidade de determinada característica é fundamental em programas de melhoramento genético, pois características de baixa herdabilidade, exceto quando a 
intensidade de seleção é alta, não apresentam respostas satisfatórias ao trabalho de seleção dos animais (BOLIGON et al, 2006). Por isso, de acordo com Kempthorne (1973), o número de dados deve ser suficiente para se obter representação e com isso possibilitar a comparação com outros trabalhos. Schaeffer, Schenkel e Fries (1998) comentam que o melhor método para a avaliação de animais selecionados não depende apenas do processo de seleção, mas também das informações disponíveis e do critério para julgar métodos alternativos. Geralmente dois tipos de informação estão disponíveis: os registros dos animais e dos seus parentes (a posteriori), e o conhecimento sobre a população específica de onde o animal está inserido (informação a priori).

As características do objetivo do melhoramento não são necessariamente as mesmas dos critérios de seleção as quais são medidas e usadas na tomada de decisões para seleção. O conhecimento da correlação genética entre essas duas características permite aos métodos de índice de seleção alcançar o primeiro usando os dados do último (KINGHORN, 2006). Gunski et al. (2001) observaram que os pesos e ganhos de peso a diferentes idades têm sido freqüentemente incluídos nos programas de seleção em gado de corte, com base, fundamentalmente, nas altas correlações existentes entre eles.

Segundo Olson et al. (2006), a resposta à seleção é proporcional à correlação entre o mérito genético verdadeiro dos indivíduos e o mérito predito a partir de mensurações fenotípicas, também conhecida como acurácia. A coleta de dados adicionais normalmente aumenta o conhecimento sobre essa correlação e conseqüentemente, permite uma maior avaliação do potencial da resposta.

Nos últimos anos, os métodos de predição de valores genéticos têm sofrido várias modificações, acompanhando o progresso na capacidade operacional dos computadores e o desenvolvimento de técnicas estatísticas e relacionadas à predições de efeitos aleatórios, corrigidos para os diferentes efeitos, mais acurados, bem como, a utilização de algoritmos computacionais cada vez mais sofisticados e eficientes. Esse desenvolvimento de novas técnicas tem visado o aumento da acurácia das predições, dependendo dos dados que se dispõem a analisar, do método estatístico e dos tipos de modelos utilizados (ELER, 1994; FERREIRA et al., 1999). Os componentes de variância têm sido estimados por diferentes métodos, que vêm evoluindo à medida que novas técnicas computacionais e novas teorias têm sido desenvolvidas e implementadas. O desenvolvimento de programas de melhoramento bem estruturados depende de um acurado conhecimento dos parâmetros genéticos, fenotípicos, assim como, dos fatores ambientais que influenciam a população a ser melhorada (FERRAZ, 1993; KOOTS \& GIBSON, 2006). O conhecimento das propriedades genéticas 
nos rebanhos baseia-se na estimação dos chamados parâmetros genéticos, o que, em genética quantitativa, é sinônimo de estimação de componentes de (co)variância e composição de combinações lineares destes componentes, os quais tem por base a variação existente nas observações (fenótipos) e o relacionamento entre indivíduos de diferentes gerações para determinada característica ou quando se considera mais de uma característica (ELER, 1994). A estimação desses parâmetros em programas de melhoramento é de grande relevância, haja vista as mudanças ocorridas na população, uma vez que estes parâmetros são utilizados nas predições de valores genéticos e na predição da resposta à seleção (PEREIRA et al., 2006).

Dessa forma, a DEP, que indica a capacidade de transmissão genética de determinado indivíduo, é muito utilizada na bovinocultura de corte, uma vez que pela forma como ela é predita, permite com que seja utilizada como um atributo de comparação. Assim, dentro de uma população que foi submetida a uma avaliação genética, pode-se decidir sobre a utilização de dois animais comparando-se suas DEPs (EUCLIDES FILHO, 1999; BIF, 2005). Porém, a segurança com a qual as DEPs são estimadas também pode variar. Esta segurança recebe vários nomes, sendo o mais comum, em gado de corte, acurácia. A acurácia de uma estimativa é uma medida da correlação entre o valor genético predito e os valores genéticos reais, ou seja, mede o quanto a predição obtida está relacionada com o "valor genético real" do parâmetro, dando-nos a "confiabilidade" da estimativa ou valor genético (VAN VLECK, 1993). A acurácia, no entanto, não depende somente do número de filhos de um reprodutor que foram medidos, mas, principalmente do número de parentes medidos que esse reprodutor teve. Contudo altas acurácias só são conseguidas a partir de muitas informações a respeito do animal que está sendo testado, geralmente obtidas a partir de um grande número de filhos. Isto significa mais tempo entre o nascimento desse reprodutor e seu uso no rebanho, o que aumenta o intervalo entre gerações e diminui o ganho genético por ano. Assim, usar animais jovens, com baixa acurácia, pode aumentar o risco, mas se a avaliação for bem feita, o mérito genético do rebanho como um todo cresce mais rapidamente do que se utilizar touros "provados", com altas acurácias. De acordo com Resende e Perez (1999), geralmente, quanto maior a acurácia em uma avaliação de um animal, maior será a confiança na avaliação e no valor genético predito deste animal.

Para cada DEP é obtida uma acurácia, sendo usualmente publicados em conjunto. A acurácia varia de 0 (zero) a 1 (um), sendo que quanto mais próxima de 1 , maior a confiança na predição da DEP. A acurácia é obtida no processo de avaliação genética. A expressão mais utilizada para calculá-la foi proposta pelo Beef Improvement Federation (BIF), uma instituição dos Estados Unidos, e pode ser definida como: 


$$
\text { Acurácia }=1-\sqrt{\frac{P E V}{\delta_{a}^{2}}}
$$

em que PEV (Prediction Error Variance) é o elemento da diagonal do inverso da matriz Left Hand Side $\left(\mathrm{LHS}^{-1}\right)$, relativo ao animal para qual foi calculado a DEP e $\sigma_{\mathrm{a}}{ }^{2}$ é a variância genética aditiva da característica em estudo. Como a $\sigma_{\mathrm{a}}{ }^{2}$ é constante para cada avaliação, a acurácia associada a DEP de cada animal varia de acordo com o seu PEV. As DEPs seguem distribuição normal e esta comparação envolve o conceito de média (BERGMANN, 2004).

\subsection{Características estudadas nos programas de melhoramento genético de bovinos de corte}

Os programas de melhoramento genético de gado de corte no Brasil incluem inúmeras características. Dentre essas, as características de crescimento são bastante importantes em programas de seleção, uma vez que são fáceis de medir e interpretar e apresentam coeficientes de herdabilidade medianos ou mesmo altos, respondendo bem à seleção (FERREIRA et al.,1999; MERCADANTE, LÔBO e OLIVEIRA, 2000; SILVA et al., 2003). Porém, a relativa importância dos efeitos genéticos aditivos direto e materno para crescimento devem ser considerados quando os produtores formulam a estratégia de melhoramento (FERREIRA et al., 1999). As avaliações genéticas com a disponibilidade da diferença esperada na progênie (DEP) têm sido uma ferramenta fundamental para a obtenção de progresso genético nos rebanhos de corte (SILVA et al., 2003).

Com o aumento da produção de animais precoces, o peso à desmama tornou-se muito importante, pois, dependendo da idade de abate, aproximadamente 50\% do peso final é atingido até os 7 meses de idade. Os pesos de nascimento e desmama são determinados não somente pelo animal, mas também pelo ambiente materno, representado principalmente pela produção de leite e habilidade materna (MEYER, 1992; FRIES, 1996; PAZ et al., 1999). Garnero et al. (2002) comentam que do ponto de vista prático de seleção, o peso à desmama é o melhor critério e o mais interessante economicamente.

Já o ganho de peso no período pós-desmama é uma excelente característica a ser estudada, pois permite avaliar o potencial genético do indivíduo, visto que esse potencial não é mais influenciado pelo efeito materno (FRIES, 1996; LEE et al., 2000; BOLIGON et al., 2006). A separação da fração genética da ambiental e a determinação da importância relativa dos efeitos aditivos genéticos diretos são necessárias quando se pretende formular estratégias de melhoramento animal (BROWN et al., 1993; FERREIRA et al., 1999; PANETO et al., 
2002), principalmente na fase pós-desmama, quando esses efeitos têm grande influência na resposta do animal.

Segundo Lee e Bertrand (2002), em estudos envolvendo populações da raça Hereford, o ganho de peso pós-desmama mostra-se afetado pelo efeito da interação genótipo $\mathrm{x}$ ambiente. Cintra (2007) e Ribeiro (2005) também relatam o efeito da interação em estudos envolvendo bovinos compostos e Nelore, respectivamente. Além disso, a alta correlação genética encontrada entre peso a desmama e tamanho corporal, da ordem de 0,97 , indica que a seleção para peso à desmama estará promovendo um aumento no tamanho por resposta correlacionada (CARDOSO et al., 1998). Correlações genéticas de alta magnitude foram reportadas por Bullock, Bertrand e Benyshek (1993) entre pesos às idades jovens, como peso ao nascer, peso a desmama, peso aos 12 meses de idade e ganho de peso da desmama ao ano. Mercadante et al., (2003) comentam que respostas diretas para peso ao sobreano e respostas correlacionadas com pesos ao nascimento e à desmama tem sido descritos.

\subsection{CEIP (Certificado Especial de Identificação e Produção)}

Em 1995, o Ministério da Agricultura, Pecuária e Abastecimento (MAPA) instituiu o Certificado Especial de Identificação e Produção - CEIP, para bovinos resultantes de cruzamentos planificados e para animais de raças puras com aptidão para corte, que avaliados geneticamente obtenham classificação superior dentro do grupo de animais submetidos à seleção, iniciando com os $20 \%$ melhores animais e chegando ao limite de $30 \%$ conforme progresso do programa de melhoramento, conforme portarias ministeriais $n^{0} 267$, de maio de 1995 e n 22, de agosto de 1995.

Porém, para se obter o certificado, um projeto deve especificar o material genético a ser melhorado, a metodologia de avaliação genética a ser utilizada deve contar com supervisão técnica de profissional habilitado, além de identificar a instituição ou técnico responsável pelas avaliações genéticas do rebanho.

O modelo do certificado (CEIP) deve ter padrão especificado no projeto, com o seguinte plano de destaque:

- CEIP - Certificado Especial de Identificação e Produção;

- Nome e logotipo do detentor do credenciamento;

- Número do credenciamento concedido pelo Ministério da Agricultura, Pecuária e Abastecimento;

- Sistema de validação. 
O uso de genética de qualidade constitui-se em uma ferramenta indispensável na produção de novilhos precoces, os quais ao serem abatidos, fornecem carne de qualidade e em tempo reduzido. Touros com CEIP são comprovadamente qualificados e aptos a produzir mais e com melhor qualidade, servindo de garantia de melhoria da produtividade para o criador. Nesse sentido, o objetivo dessa seleção é oferecer ao mercado reprodutores qualificados e capazes de produzir bezerros ou bezerras de melhor qualidade. Dentre algumas empresas que possuem programas reconhecidos nacionalmente com CEIP, pode-se destacar a Agro- Pecuária CFM Ltda, a Agropecuária Jacarezinho Ltda. e o Programa PAINT da Central de Inseminação Artificial Lagoa da Serra Ltda., dentre outros.

\subsection{Estatísticas descritivas - Medidas de tendência central e de dispersão}

As medidas de posição e de dispersão fornecem importantes informações de locação e de variabilidade da distribuição de referência. A forma de distribuição dos dados é extremamente importante, pois a partir de seu conhecimento é que pode-se escolher entre os modelos disponíveis, assim como, a estratégia de análise adequada.

Todas as diferentes fontes de informação são tomadas como desvio da média, podendo ser uma média populacional. Porém, se os animais produzirem em diferentes anos e/ou rebanhos, será mais apropriado tomar as observações como desvio da média do ano e/ou do rebanho (VAN DER WERF, 2006).

Assim sendo, partindo-se da idéia dos diferentes critérios de seleção, Muniz et al. (2005) evidenciaram que critérios de seleção baseados na média harmônica distinguiram touros com mérito genético maior e progênie mais uniforme. De acordo com Ferreira (2005), a média harmônica é obtida tomando-se o recíproco da média aritmética dos recíprocos. Triola (1999) cita que a mesma costuma ser usada como medida de tendência central para conjuntos de dados que apresentem taxas de variação, podendo ser descrita pela seguinte fórmula:

$$
\frac{1}{H}=\frac{1}{n} \sum_{i=1}^{n} \frac{1}{X_{i}} \quad \text { ou ainda } \quad H=\frac{n}{\sum_{i=1}^{n} \frac{1}{X_{i}}},
$$

em que $H$ é a média harmônica de $n$ progênies de $X_{i}$ (em que $i=1, \ldots ., n$ ).

Streiner (2000) sugere que a determinação de amostras quando esta varia de acordo com grupos pode ser bem representada pela média harmônica.

A maior parte das discrepâncias entre os dois critérios pode ser atribuída às diferenças 
de conceitos entre as médias aritmética e harmônica. As duas estatísticas serão iguais somente quando a população observada for uniforme (todas as informações iguais e variância igual a zero) ou quando $n=2$. Por outro lado, a média harmônica sempre será menor que a aritmética e será maior se a população tornar-se muito heterogênea (ORTIZ-PEÑA et al., 2004). Estudos simulados por Carvalheiro et al. (2001) mostraram que 95-99\% das diferenças entre os dois critérios pode ser explicado pela diferença na variabilidade da progênie.

Nas distribuições simétricas, os mesmos valores são obtidos para a moda, para a mediana e para a média. Contudo, nas assimétricas, essas medidas são diferentes e podem ser usadas para avaliar indiretamente a forma da distribuição. Algumas delas estão relacionadas à simetria da distribuição e outras ao grau de achatamento, tomando-se como referência o modelo da função densidade de probabilidade da distribuição normal (FERREIRA, 2005).

Para se analisar os coeficientes de assimetria e curtose, deve-se inicialmente observar os momentos populacionais e os momentos centrados na média e seus respectivos estimadores, sendo o $r$ a ordem do momento, isso para uma população finita. O momento de primeira ordem ( $\mathrm{r}=1)$ é sempre igual a zero; o momento centrado na média de ordem 2 é a variância da população; o de ordem 3 é o momento de assimetria e o de ordem 4, momento de curtose (COSTA NETO, 1977; FERREIRA, 2005). As equações de momentos e seus estimadores, respectivamente, podem ser visualizadas a seguir.

$$
\begin{gathered}
\mu_{\mathrm{r}}=\frac{\sum_{i=1}^{N}\left(X_{i}-\mu\right)^{r}}{N} \\
m_{r}=\frac{\sum_{i=1}^{n}\left(X_{i}-\bar{X}\right)^{r}}{n}
\end{gathered}
$$

A assimetria procura caracterizar como e quanto a distribuição das freqüências se afasta da condição de simetria (COSTA NETO, 1977). O coeficiente de assimetria populacional ( $\sqrt{\beta}_{1}$ ) é uma forma padronizada do estimador do momento de assimetria $(\mathrm{r}=3)$. As populações cujas distribuições são simétricas apresentam valor de $\sqrt{\beta}_{1}=0$; as populações assimétricas à direita (assimetria positiva) apresentam $\sqrt{\beta}_{1}>0$ e as assimétricas à esquerda (assimetria negativa) apresentam $\sqrt{\beta}_{1}<0$, (TRIOLA, 1999; FERREIRA, 2005), como pode ser visto na Figura 1.

$$
\sqrt{b}_{1}=\frac{m_{3}}{\left(m_{2}\right)^{3 / 2}} \quad \text { (amostral) }
$$



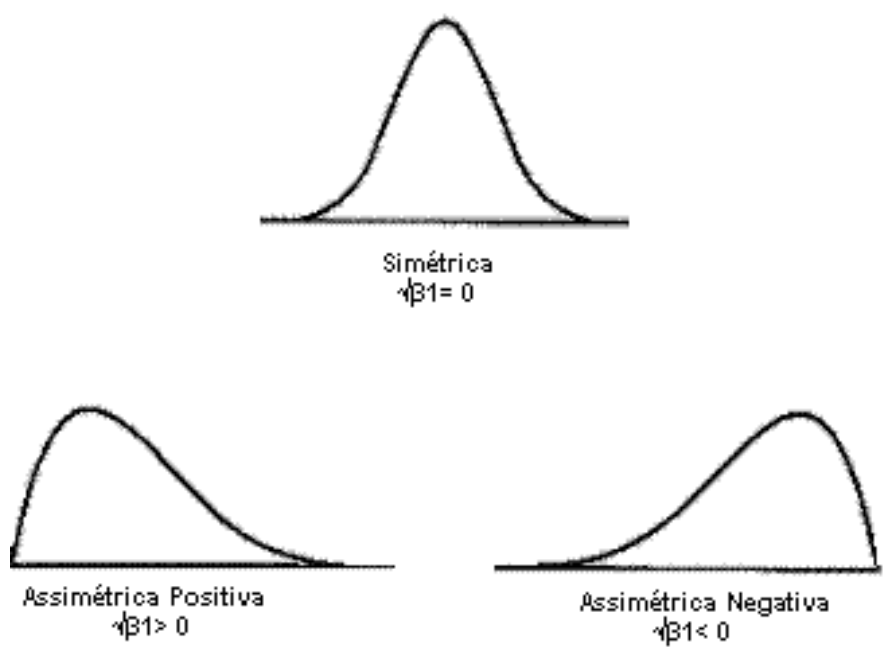

Figura 1 - Curvas de distribuição de dados populacionais simétricos e assimétricos

Adicionalmente, o coeficiente de curtose diz respeito ao grau de achatamento de uma distribuição. Para medir a curtose, define-se o estimador (ck) do coeficiente de curtose na expressão abaixo:

$$
b_{2}=\frac{m_{4}}{\left(m_{2}\right)^{2}} \text { ou } c k=\frac{m_{4}}{S^{4}}
$$

na qual $S^{4}$ refere-se ao desvio-padrão elevado à quarta potência ou à variância ao quadrado.

As distribuições que possuem valor de curtose igual a 3 são denominadas mesocúrticas. Aquelas que possuem $\beta_{2}>3$ são denominadas leptocúrticas e as que possuem $\beta_{2}<3$ são as platicúrticas. As distribuições leptocúrticas são aquelas que possuem uma concentração de valores próxima ao valor central maior que a da distribuição normal (mesocúrtica). Nas distribuições platicúrticas, por sua vez, ocorre o contrário, ou seja, uma menor concentração de valores em torno do centro da distribuição (FERREIRA, 2005). A representação gráfica da curtose pode ser evidenciada na Figura 2.

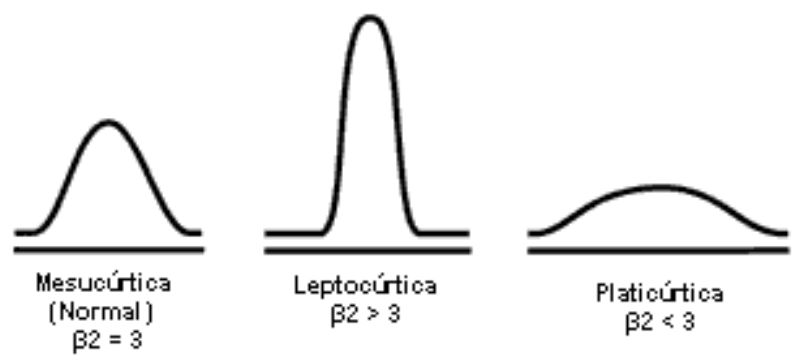

Figura 2 - Curvas de distribuição de populações de acordo com o coeficiente de curtose 
A distribuição normal é a mais importante distribuição de probabilidade estatística, sendo a base da maioria das técnicas utilizadas (Figura 3). Além disso, inúmeros são os fenômenos aleatórios cujos comportamentos podem ser descritos precisamente ou de forma aproximada pelo modelo probabilístico normal. A distribuição normal é a forma limitante de muitas outras distribuições de probabilidades, como conseqüência do teorema central do limite, o qual preconiza que quanto maior o tamanho da amostra, mais a forma da distribuição amostral da média aproxima-se da forma da normal, mesmo que a distribuição da variável em questão não seja normal (FERREIRA, 2005).

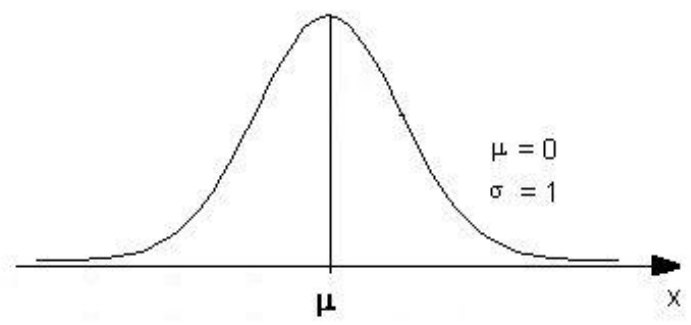

Figura 3 - Curva da distribuição normal padronizada de probabilidade ou normal reduzida 


\section{HIPÓTESES}

O estudo das informações contidas na literatura e a proposta de uso de média harmônica da metade dos valores genéticos aditivos das progênies para expressar a diferença esperada da progênie (DEP) de touros permitem que se levantem as seguintes hipóteses:

$\mathrm{HO}_{1}$ : Não existe diferença na estimação de DEPs nas diferentes metodologias propostas. $\mathrm{Ha}_{1}$ : Existe diferença na estimação de DEPs nas diferentes metodologias propostas.

$\mathrm{HO}_{2}$ : A estimação de DEPs de touros expressa como média harmônica das DEPs de seus filhos não penalizará touros que deixam descendentes com DEPs mais dispersas do que outros.

$\mathrm{Ha}_{2}$ : A estimação de DEPs de touros expressa como média harmônica das DEPs de seus filhos poderá penalizar touros que deixam descendentes com DEPs mais dispersas do que outros. 


\section{OBJETIVOS}

O presente estudo teve com objetivos:

(i) Estimar a diferença esperada na progênie (DEP) de touros da raça Nelore, utilizados em programa de seleção destinados à obtenção de CEIP (Certificado Especial de Identificação e Produção) para as características peso à desmama (PD), peso ao sobreano (PS) e ganho de peso da desmama ao sobreano (GP), utilizando-se dos seguintes critérios:
a. média aritmética das DEPs dos filhos
b. média harmônica das DEPs dos filhos
c. média harmônica das DEPs dos filhos acrescida da média da característica estudada.

(ii) Comparar essas metodologias de estimação;

(iii) Observar a viabilidade da utilização da média harmônica como uma estimativa que ajusta o valor genético aditivo de um touro para a dispersão dos valores genéticos de suas progênies. 


\section{MATERIAL E MÉTODOS}

\subsection{Origem dos dados}

Os dados analisados neste estudo foram obtidos junto ao Grupo de Melhoramento Animal “Prof. Dr. Gordon Dickerson”, pertencente ao Departamento de Ciências Básicas da Faculdade de Zootecnia e Engenharia de Alimentos da Universidade de São Paulo (GMA/FZEA/USP), localizado em Pirassununga, São Paulo. Os dados referem-se a um rebanho da raça Nelore, situado na Fazenda São Francisco, município de Magda (2045’S; $50^{\circ} 30^{`} W$ ), região oeste do Estado de São Paulo, pertencente à empresa Agro-Pecuária CFM Ltda.

A propriedade pode ser caracterizada como de alto padrão na pecuária brasileira e seu sistema administrativo suporta com eficiência o grande número de informações que um programa de melhoramento exige. Conta ainda com adequada infra-estrutura de pastagens e demais instalações e com máquinas e implementos agrícolas em quantidades suficientes para as práticas de manejo de pastagens e de animais existentes.

O rebanho é explorado para a venda de matrizes e touros geneticamente avaliados. O sistema de criação adotado é a pasto, com disponibilidade de forragem de boa qualidade nutricional, suplementação mineral e água à vontade. As pastagens são predominantemente constituídas por capins do gênero braquiária (Brachiaria decumbens e Brachiaria brizantha) e Panicum (Panicum maximum). Os animais são vacinados contra febre aftosa, brucelose, carbúnculo, pneumoenterite e raiva, praticando-se também o controle de endo e ectoparasitos. Quando ocorre qualquer atividade de manejo diferenciado, isto é feito sem descaracterizar os grupos de manejo, ou seja, todos os animais de um lote ou grupo são sempre submetidos ao mesmo tratamento.

O manejo reprodutivo dos animais envolve controle das condições sanitárias e do desenvolvimento reprodutivo dos animais jovens. Os animais jovens só são designados para a reprodução depois de passar por minucioso exame clínico e andrológico, comprovando assim a habilidade reprodutiva.

\subsection{Dados analisados}

Foram analisados os pesos à desmama, ao sobreano e o ganho de peso pós-desmama. O conjunto inicial dos dados constava de 81.500 animais com alguma mensuração válida. Observa-se na Tabela 3 a freqüência de animais, o número total de grupos de contemporâneos 
(GCs), o número de touros e vacas para cada característica avaliada neste estudo.

Tabela 3 - Freqüência absoluta de informações para as características no banco de dados

\begin{tabular}{ccccc}
\hline Característica & Freqüência de animais & $\mathrm{N}^{0}$ GCs & $\mathrm{N}^{\mathrm{o}}$ Touros & $\mathrm{N}^{\mathrm{o}}$ Vacas \\
\hline PD & 45.014 & 961 & 359 & 19.223 \\
PS & 45.014 & 1.095 & 359 & 18.240 \\
GP & 45.014 & 1.090 & 359 & 18.208 \\
\hline PD - peso à desmama; PS - peso ao sobreano; GP - ganho de peso da desmama ao & sobreano.
\end{tabular}

A análise de consistência dos dados foram realizadas utilizando-se o software Microsoft Visual FoxPro ${ }^{\circledR}$, versão 9.0. Os dados foram editados para eliminar registros que apresentassem erros e informações incompletas. Com esses dados foi formado o conjunto de dados da Fazenda São Francisco, no qual constam todas as características de produtividade dos animais coletados, grupos de contemporâneos, bem como idades de medição e/ou pesagem. As definições dos grupos de contemporâneos (GC) foram caracterizadas combinando-se a safra de nascimento, o sexo do bezerro, a fazenda e o grupo de manejo do animal nas respectivas fases de mensuração. A importância da formação dos grupos de contemporâneos para análise genética está em reunir em grupos distintos animais que foram submetidos a oportunidades diferentes de desenvolvimento determinadas por fatores não genéticos. Com essa classificação em grupos de contemporâneos, procura-se definir com clareza categorias que representem com bastante fidelidade as oportunidades de manejo, alimentação, nutrição, saúde e outras variáveis de ambiente que podem afetar o desempenho dos animais.

Após a formação, os GCs foram analisados em relação as suas respectivas características, buscando grupos que pudessem interferir negativamente na qualidade das análises. Para tanto, foram eliminados os GCs:

a) com menos de 5 animais;

b) formados por animais filhos de um único touro;

c) informações fora de amplitude aceitável.

Esse conjunto foi utilizado para análises preliminares feitas pelo MTDFREML Multiple Trait Derivative Free Restricted Maximum Likelihood (BOLDMAN et al., 1995), para predição dos valores genéticos e posteriormente, as diferenças esperadas de progênie de todos os animais. 
Posteriormente as DEPs foram calculadas pelas três metodologias, com o uso do software Statistical Analysis System (SAS), versão 9.1.

Os animais que apresentaram mensurações corresponderam a um arquivo de pedigree é composto por 456.222 animais, sendo desses, 1.417 touros e 150.882 vacas.

Um banco de dados comumente apresenta valores discrepantes ou dispersos, chamados de outliers, que por não serem representativos do banco de dados, devem ser corretamente identificados e eliminados. Porém, antes de eliminá-los, é conveniente ter conhecimento das causas que levam ao seu aparecimento. Em muitos casos as razões da sua existência determinam as formas como devem ser tratadas. Assim, as principais causas que levam ao aparecimento de outliers são: erros de medição, erros de execução e variabilidade inerente dos elementos da população. O critério utilizado para a exclusão dos dados discrepantes foi embasado no Teorema do Limite Central, pelo qual numa distribuição amostral de média $\bar{X}$ e desvio-padrão S, a média \pm 3 desvios conterá aproximadamente 99\% das observações.

\subsection{Metodologia}

Os componentes de (co) variância e os parâmetros genéticos foram estimados pelo método da máxima verossimilhança restrita (REML), utilizando-se o software MTDFREML (BOLDMAN et al., 1995). No modelo animal completo foram usadas todas as informações disponíveis de pedigree. Essas análises foram realizadas pelos professores responsáveis pela avaliação genética do rebanho.

O método de máxima verossimilhança tem sido comumente utilizado para a estimação de componentes de (co)variância por fornecer estimativas dentro do espaço paramétrico, usar todas as informações do pedigree e por fornecer estimativas não viesadas sob seleção.

As análises consideraram o modelo matemático completo para peso à desmama descrito abaixo:

$$
y=X b+Z a+W m+S c+e
$$

Em que:

$\boldsymbol{y}=$ vetor de observações da característica em questão;

$\boldsymbol{X}=$ matriz de incidência dos efeitos fixos, associando os elementos de $\boldsymbol{b}$ a $\boldsymbol{y}$;

$\boldsymbol{b}=$ vetor dos efeitos fixos representados pelos grupos de contemporâneos;

$\boldsymbol{Z}, \boldsymbol{W}$ e $\boldsymbol{S}$ são as matrizes de incidência dos efeitos aleatórios, associando respectivamente os 
elementos de $\boldsymbol{a}, \boldsymbol{m}$ e $\boldsymbol{c}$ a $\boldsymbol{y}$;

$\boldsymbol{a}$ é o vetor de efeitos aleatórios genéticos aditivos diretos;

$\boldsymbol{m}$ é o vetor de efeitos aleatórios genéticos aditivos maternos;

c é o vetor de efeitos aleatórios não correlacionados do ambiente permanente materno;

$\boldsymbol{e}$ é o vetor de efeitos residuais inerentes a cada observação.

Como resultados dessas análises, foram obtidas as estimativas das Diferenças Esperadas de Progênie (DEP) dos touros e das suas progênies para as características PD, PS e GP. Obtiveram-se estimativas de DEP de 359 touros, todos com 20 ou mais filhos. Foram considerados touros os animais machos que apresentem pelo menos duas progênies (em grupos contemporâneos diferentes) durante sua vida reprodutiva.

Para se estimar as DEPs, foram utilizados componentes de variância genética aditiva, a variância genética materna, a variância do erro, a variância fenotípica, a variância permanente de ambiente e a covariância genética aditiva com materna, previamente estimados.

Com o objetivo de verificar a diferença existente entre as metodologias de estimativas de DEPs de touros pela média aritmética e pela média harmônica e por conseqüência, a classificação dos touros em ambas, foram utilizadas três metodologias para estimação das DEPs, descritas a seguir:

- Metodologia M (DEPm): média aritmética das DEPs dos filhos dos touros;

- Metodologia HK (DEPhk): DEP calculada a partir das DEPs dos filhos do touro analisado, acrescida de uma constante (K), que é a média aritmética da característica em questão e posterior aplicação da média harmônica. Essa metodologia guarda alguma semelhança à proposta utilizada pelo Sumário PAINT, da Lagoa da Serra, que também adiciona uma constante, denominada Alvo;

$$
D E P h k=\frac{n}{\sum_{i=1}^{n} \frac{1}{D E P_{i}+K}}
$$

- Metodologia HS (DEPhs): DEP calculada a partir das DEPs dos filhos dos touros aplicada à fórmula da média harmônica, como descrito abaixo.

$$
\text { DEPhs }=\frac{n}{\sum_{i=1}^{n} \frac{1}{D E P_{i}}}
$$

em que n é o número de progênies do touro e $\mathrm{DEP}_{\mathrm{i}}$ é a DEP de n progênies i do touro em 
questão (em que i $=1,2,3, \ldots ., n)$.

Para se evitar problemas com denominador igual a zero, na metodologia HS, tomou-se o cuidado de transformar toda DEP igual a zero em 0,01. Ainda nessa metodologia, foram conservados os valores negativos de DEP e submetidos à fórmula da média harmônica. Porém, não foi utilizada a função HARMEAN do SAS, a qual não admite valores negativos, mas sim funções básicas de soma e divisão. O problema com estimativas negativas na aplicação da média harmônica deve-se ao fato da presença de valores muito próximos a zero, e não o negativo em si. Essa proximidade do zero faz com que a estimativa tenha tendência ao infinito, em função da presença do referido valor no denominador. Por isso, a média harmônica costuma ser usada em casos de contagem, como velocidades, custos e população (HARIKI, 2004).

Foi verificada também a proporção de animais discordantes entre os modelos, ao serem selecionados os 10, 25 e 50\% touros com DEPs superiores e inferiores em cada metodologia. Além disso, foram calculados médias, desvios-padrão, coeficientes de curtose e assimetria para os touros discordantes, com a finalidade de se estudar a variabilidade das características estudadas nas progênies dos touros. Para a nomenclatura das tabelas, tomou-se como nome as palavras “top” e "bot”, originárias do inglês top e bottom, que significam, respectivamente, parte superior e inferior da classificação.

Para definir os touros discordantes e calcular suas respectivas estatísticas descritivas utilizou-se basicamente o PROC MEANS e PROC SORT, do SAS, versão 9.1, através de expressões condicionais (IF - THEN). Essas expressões são mutuamente exclusivas, dando origem às tabelas com os touros selecionados por cada metodologia, de acordo com a porcentagem requerida. A partir dessas tabelas, foram obtidas estatísticas descritivas dos touros selecionados por cada uma das metodologias, para posterior comparação.

A taxa de discordância foi calculada a partir do número de touros discordantes e o número total de touros selecionados para cada porcentagem requerida.

Utilizando-se as porcentagens de classificação, foram calculados os coeficientes de correlação de Pearson e de Spearman entre as diferenças esperadas na progênie (DEP). Este último permite quantificar o grau de associação entre os resultados obtidos por duas avaliações. O rank foi estabelecido pela classificação das diferenças esperadas na progênie (DEP) dos animais em cada modelo. 


\section{RESULTADOS E DISCUSSÃO}

\subsection{Estatística Descritiva}

As estatísticas descritivas dos dados para PD, PS e GP dos animais são apresentadas na Tabela 4. As médias, os desvios-padrão e os coeficientes de variação observados são similares aos encontrados em outros estudos (ELER et al. 2000; EVERLING et al. 2001; TEIXEIRA e ALBUQUERQUE, 2003; MOURÃO, 2005). O valor da média das características em questão é a constante (K), a qual foi utilizada para as análises posteriores.

Tabela 4 - Número de observações (N), Média, Desvio-padrão (DP), Coeficiente de Variação (CV), Mínimo (Min) e Máximo (Max) das características analisadas

\begin{tabular}{lcccccc}
\hline Característica & N & Média & DP & CV (\%) & Min & Max \\
\hline PD (Kg) & 45.014 & 181,41 & 25,63 & 14,13 & 53,00 & 303,00 \\
PS (Kg) & 45.014 & 301,98 & 43,52 & 14,41 & 88,00 & 598,00 \\
GP (Kg) & 45.014 & 115,06 & 31,71 & 27,56 & 1,01 & 334,34 \\
\hline
\end{tabular}

PD - peso à desmama;; PS - peso ao sobreano; GP - ganho de peso da desmama ao sobreano.

Pode-se verificar que as características peso à desmama e peso ao sobreano apresentaram menores variabilidades, fato evidenciado pela dimensão de seus respectivos coeficientes de variação. A característica ganho de peso da desmama ao sobreano mostrou-se mais variável, o que proporcionou aumento na estimativa do coeficiente de variação. Porém, quando se observa o desvio-padrão das características, nota-se que o maior deles está relacionado ao peso ao sobreano, contrariando a idéia de menor variabilidade sugerida pelo coeficiente de variação. Talvez uma causa disso seja a época em que os bezerros são desmamados, no início da seca, fazendo com que eles fiquem muito estressados e percam peso.

\subsection{Peso à desmama}

Para as estimativas de DEP de peso à desmama, foram considerados 45.014 animais. Na Tabela 5 pode ser vista a estatística descritiva das diferentes metodologias. 
Tabela 5 - Estatística descritiva das metodologias de estimação de DEP para peso à desmama: média, desvio-padrão (DP), mínimo (Min) e máximo (Max)

\begin{tabular}{ccccc}
\hline & Média & DP & Min & Max \\
\hline M & 6,03 & 2,80 & $-1,86$ & 14,24 \\
HK & 186,99 & 2,80 & 179,06 & 195,19 \\
HS & 2,07 & 53,48 & $-956,06$ & 190,64 \\
\hline
\end{tabular}

Pode-se notar pequena variação quanto à capacidade de ajuste dos modelos, M e HK, baseando-se apenas no desvio-padrão. O desvio-padrão do modelo HS é considerado alto, porém pode ser explicado pela grande magnitude da amplitude de valores. A média de HK apresenta-se muito superior às demais devido à adição de uma constante às DEPs dos filhos dos touros. Para peso à desmama, a constante K é representada pela média da característica, a qual corresponde a $181 \mathrm{~kg}$.

$\mathrm{Na}$ Tabela 6, encontram-se as análises referentes aos touros discordantes entre as metodologias de estimação.

Tabela 6 - Comparação entre as metodologias HS e M, para os touros discordantes do topo da classificação para a característica peso à desmama

\begin{tabular}{|c|c|c|c|c|c|c|c|c|}
\hline & media_pd & h_pd & dp_pd & ca & ck & max_pd & min_pd & amplitude \\
\hline & \multicolumn{8}{|c|}{ TOP $10 \%$} \\
\hline media_HS & 6,3 & 23,7 & 3,1 & $-0,6$ & 1,3 & 12,7 & $-3,1$ & 15,9 \\
\hline \multirow[t]{2}{*}{ media $\mathbf{M}$} & 9,8 & 8,6 & 2,5 & $-0,4$ & 1,0 & 15,5 & 2,4 & 13,1 \\
\hline & \multicolumn{8}{|c|}{ TOP 25\% } \\
\hline media_HS & 6,1 & 20,5 & 3,1 & $-0,8$ & 1,8 & 12,8 & $-4,2$ & 17 \\
\hline \multirow[t]{2}{*}{ media $\mathbf{M}$} & 8,7 & 7,1 & 2,6 & $-0,4$ & 0,9 & 14,4 & 0,8 & 13,6 \\
\hline & \multicolumn{8}{|c|}{ TOP 50\% } \\
\hline media_HS & 4,7 & 9,7 & 2,9 & $-0,5$ & 1,3 & 11,7 & $-4,5$ & 16,3 \\
\hline media M & 7,3 & 3,5 & 3,0 & $-0,5$ & 0,5 & 13,5 & $-1,0$ & 14,5 \\
\hline
\end{tabular}

Quando se observou os touros discordantes nos métodos M e HS, notou-se que os touros selecionados pelo método HS possuem desvios-padrão ligeiramente superiores que os selecionados pelo método $\mathrm{M}$, isso para a seleção dos 10 e $25 \%$ melhores touros, indicando maior variabilidade em HS. Quando se observa a seleção dos 50\% melhores touros, o método 
M possui desvio superior, mas muito sutil em relação ao método HS. Entretanto, constatou-se que a média dos touros selecionados pelo método $\mathrm{M}$, em todas as porcentagens de seleção apresentadas, são superiores às médias dos touros selecionados pelo método HS.

Analisando-se o coeficiente de assimetria, verifica-se que os três métodos possuem assimetria negativa e mesmo se apresentando de pequena magnitude, indicam que há maior concentração de animais acima da média. Porém, o coeficiente de assimetria dos 25\% melhores touros selecionados pelo método HS é de maior magnitude que o observado pelo método $\mathrm{M}$, sugerindo que os touros selecionados pelo método HS possuem maior quantidade de progênies com DEPs acima da média.

Considerando o coeficiente de curtose, nota-se que os touros selecionados pelo método HS, para as três porcentagens em questão, apresentam coeficiente de curtose de maior magnitude que pelo método M. Assim, percebe-se que as curvas são leptocúrticas, concentrando o maior número de informações próximo à média. Porém, quando se observa a amplitude das estimativas pelos dois métodos, verifica-se que para as três porcentagens de seleção, o método HS apresenta maior amplitude. Portanto, considerando a assimetria e a curtose, os animais discordantes e selecionados pelo método HS tenderiam a ter menor variabilidade, porém, essa idéia torna-se distante quando a amplitude e o desvio-padrão são observados.

Quando se analisam os touros do topo da classificação comparando-se as metodologias M e HK entre si, percebe-se que há apenas um touro discordante entre as mesmas, referente à porcentagem de 50\% (Figura 6), não existindo discordantes nas demais porcentagens, com pode ser visto nas Figuras 4 e 5. Isso implica no fato de que as duas metodologias selecionam os mesmos touros para a característica peso à desmama, independente da porcentagem requerida, não ficando evidente a hipótese de que a média harmônica privilegia touros com maior uniformidade, como sugerido por Carvalheiro et al. (2001).

Na Tabela 7, observa-se a média das acurácias das DEPs estimadas pelos diferentes modelos.

Percebe-se que os valores de acurácia encontram-se muito próximos, independentemente da porcentagem selecionada e do método. Isso dificulta uma aferição mais precisa utilizando-se a acurácia, tornando dificultosa a tomada de decisão como base na mesma. 
Tabela 7 - Média das acurácias dos touros discordantes e selecionados por cada um dos métodos para peso a desmama

\begin{tabular}{cccc}
\hline & Top 10\% & Top 25\% & Top 50\% \\
\hline M & 0,66 & 0,67 & 0,68 \\
HK & 0,66 & 0,67 & 0,68 \\
HS & 0,68 & 0,67 & 0,69 \\
\hline
\end{tabular}

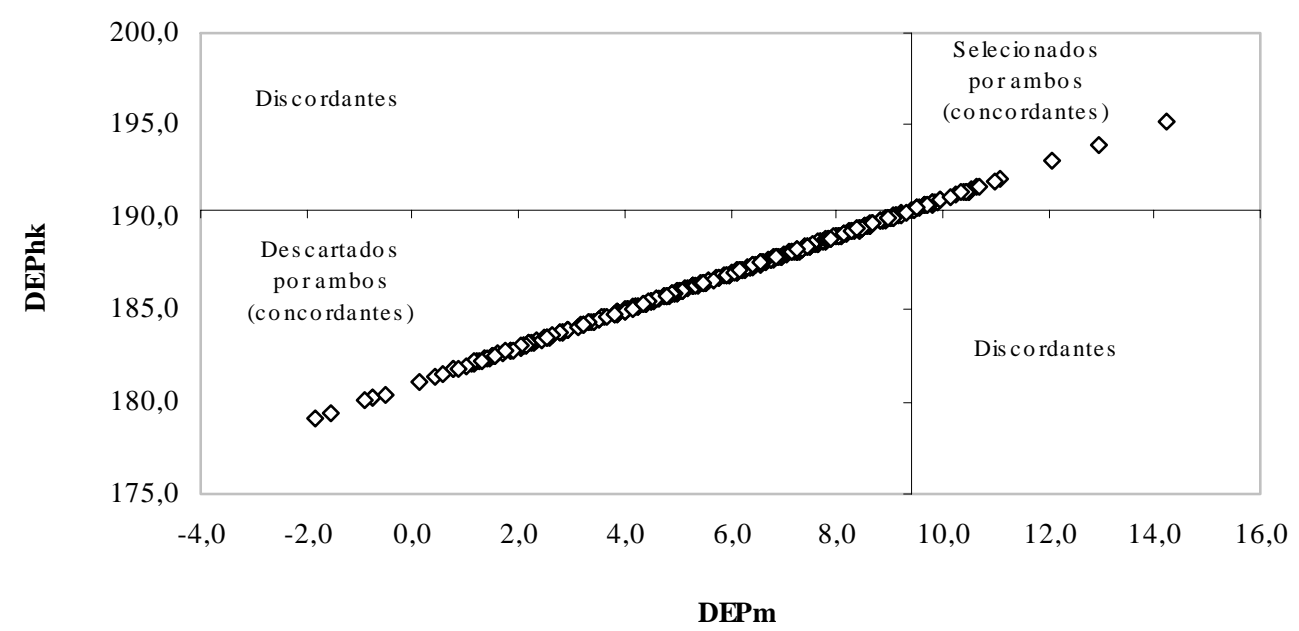

Figura 4 - Dispersões das DEPs para peso à desmama nos quadrantes definidos pelos pontos de truncamentos dos $10 \%$ melhores touros para os modelos HK (DEPhk $\geq 190,36 \mathrm{~kg})$ e M (DEPm $\geq 9,40 \mathrm{~kg})$.

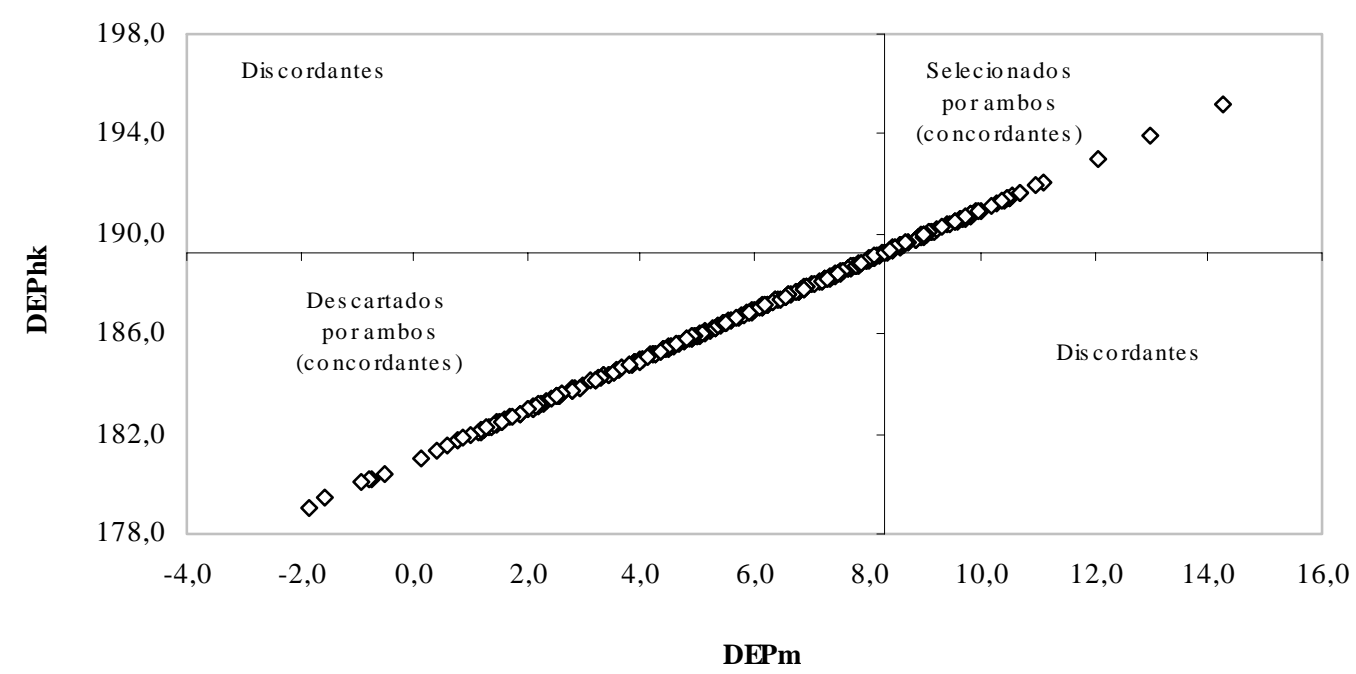

Figura 5 - Dispersões das DEPs para peso à desmama nos quadrantes definidos pelos pontos de truncamentos dos 25\% melhores touros para os modelos

HK (DEPhk $\geq 189,26 \mathrm{~kg})$ e M (DEPm $\geq 8,30 \mathrm{~kg})$. 


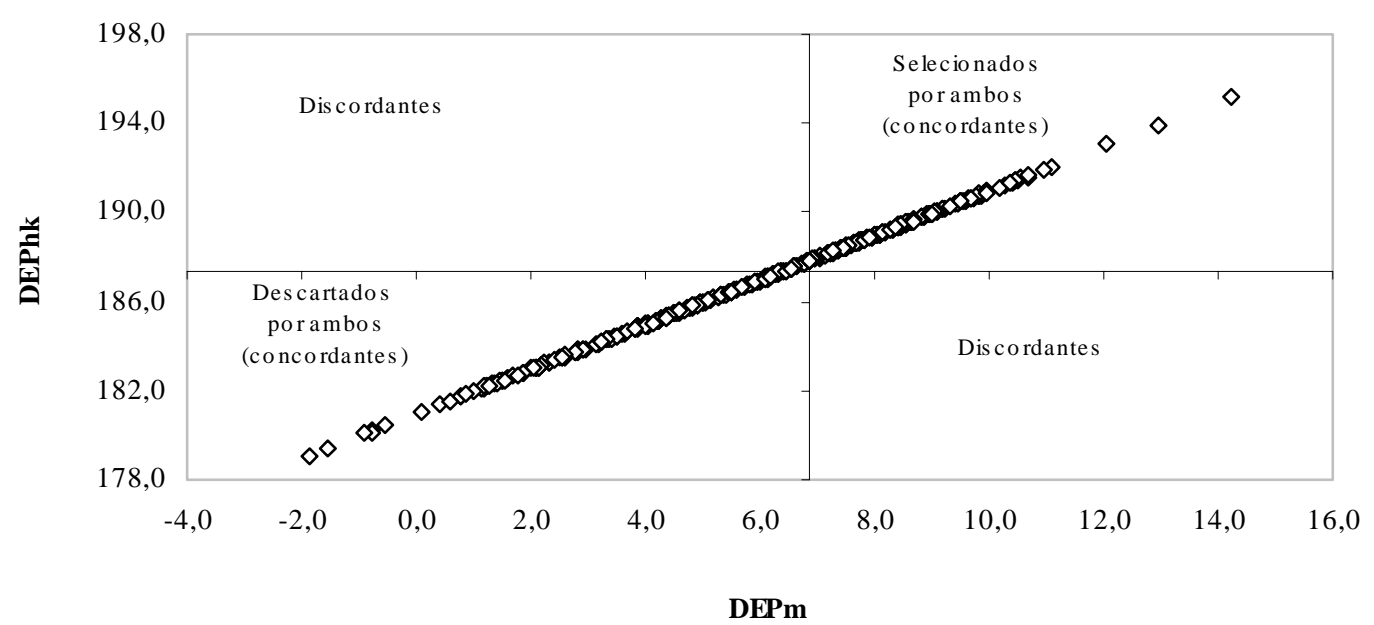

Figura 6 - Dispersões das DEPs para peso à desmama nos quadrantes definidos pelos pontos de truncamentos dos 50\% melhores touros para os modelos

HK (DEPhk $\geq 187,33 \mathrm{~kg})$ e $M(\mathrm{DEPm} \geq 6,87 \mathrm{~kg})$.

Na Tabela 8 podem ser verificadas as estatísticas empregada para a comparação entre os métodos HS e M, para os touros discordantes e descartados por cada um dos métodos, uma vez que esse touros encontram-se no final da classificação.

Tabela 8 - Comparação entre as metodologias HS e M, para os touros discordantes do final da classificação para a característica peso a desmama

\begin{tabular}{|c|c|c|c|c|c|c|c|c|}
\hline & media_pd & h_pd & dp_pd & ca & ck & max_pd & min_pd & amplitude \\
\hline & \multicolumn{8}{|c|}{ BOT $10 \%$} \\
\hline media_HS & 4,0 & $-78,4$ & 3,0 & $-0,1$ & 0,8 & 10,7 & $-3,3$ & 14,0 \\
\hline \multirow[t]{2}{*}{ media M } & 1,0 & 3,7 & 2,8 & 0,4 & 1,4 & 9,1 & $-5,5$ & 14,7 \\
\hline & \multicolumn{8}{|c|}{ BOT 25\% } \\
\hline media_HS & 5,3 & $-0,6$ & 2,9 & $-0,4$ & 0,7 & 11,8 & $-2,7$ & 14,5 \\
\hline \multirow[t]{2}{*}{ media M } & 2,8 & 6,0 & 2,7 & 0,0 & 1,9 & 10,2 & $-4,9$ & 15,1 \\
\hline & \multicolumn{8}{|c|}{ BOT 50\% } \\
\hline media_HS & 7,3 & 3,5 & 3,0 & $-0,5$ & 0,5 & 13,5 & $-1,0$ & 14,5 \\
\hline media M & 4,7 & 9,7 & 2,9 & $-0,5$ & 1,3 & 11,7 & $-4,5$ & 16,3 \\
\hline
\end{tabular}

Analisando-se os touros localizados na parte final do rank, verifica-se que, assim como acontece com os touros no topo da classificação, há a ocorrência de apenas um touro 
discordante entre os métodos $\mathrm{M}$ e HK, sendo que isso ocorre somente para os 50\%.

Quando se passa a averiguar os 10, 25 e 50\% touros de DEP inferior, comparando-se os métodos HS e M, constata-se que assim como ocorrem nos touros do topo da classificação, os touros do método HS possuem desvio-padrão levemente superior aos touros do método $\mathrm{M}$, indicando também maior variabilidade. Entretanto, observa-se que a média dos mesmos está bem acima da média dos touros do método $\mathrm{M}$, fato oposto ao que acontece com os touros localizados no topo da classificação.

Observando-se os coeficientes de assimetria e curtose, nota-se que nos $10 \%$, os touros do método HS possuem assimetria ligeiramente negativa, indicando que mesmo pertencendo ao final da classificação, possuem concentração de filhos acima da média, enquanto os do método M possuem assimetria positiva. Já nos 25\%, os touros do método HS possuem ligeira assimetria negativa e os touros do método M são considerados simétricos. Para os $50 \%$, os dois métodos são igualmente assimétricos. Com relação à curtose e à amplitude, diferentemente do que ocorre com os touros top, o método M possui maior coeficiente de curtose e maior amplitude de estimativas que o método HS para as três porcentagens de classificação.

Na Tabela 9, verifica-se que a taxa de discordância dos touros diminui à medida que a porcentagem selecionada aumenta. Isso se deve ao fato de que, provavelmente, os valores das DEPs estimadas pelos métodos HS e $\mathrm{M}$ encontram-se distantes quando se considera os animais do ápice do rank e à medida que a porcentagem selecionada aumenta, aumenta também a proximidade dos valores das DEPs estimadas pelos dois métodos em questão, como pode ser visto nas Figuras 7, 8 e 9.

Tabela 9 - Taxa de discordância (\%) entre os touros das metodologias HS e M para peso a desmama

\begin{tabular}{|c|c|c|c|}
\hline & \multicolumn{3}{|c|}{ TOP } \\
\hline & $10 \%$ & $25 \%$ & $50 \%$ \\
\hline \multicolumn{4}{|l|}{ media_HS } \\
\hline \multirow[t]{3}{*}{ media_M } & 58 & 29 & 15 \\
\hline & \multicolumn{3}{|c|}{ BOT } \\
\hline & $10 \%$ & $25 \%$ & $50 \%$ \\
\hline \multicolumn{4}{|l|}{ media_HS } \\
\hline media_M & 47 & 30 & 15 \\
\hline
\end{tabular}


classificação; media_HS: média dos touros classificados pela metodologia HS; media_M: média dos touros classificados pela metodologia $\mathrm{M}$.

As taxas de discordância dos touros menos privilegiados encontram-se similares às encontradas nos touros do topo da classificação, com exceção da classificação pelos 10\%, na qual os top possuem taxa de discordância de maior magnitude.

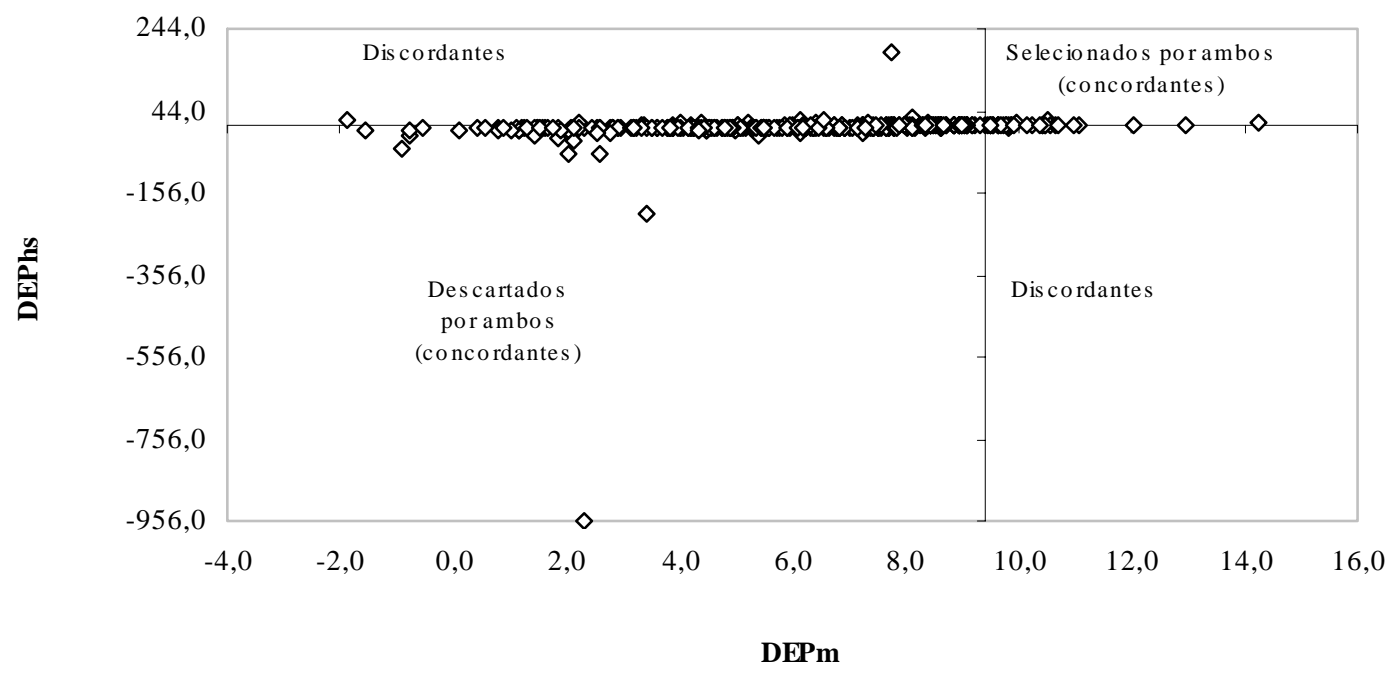

Figura 7 - Dispersões das DEPs para peso à desmama nos quadrantes definidos pelos pontos de truncamentos dos $10 \%$ melhores touros para os modelos HS (DEPhs $\geq 9,60 \mathrm{~kg})$ e $\mathrm{M}(\mathrm{DEPm} \geq 9,40 \mathrm{~kg})$.

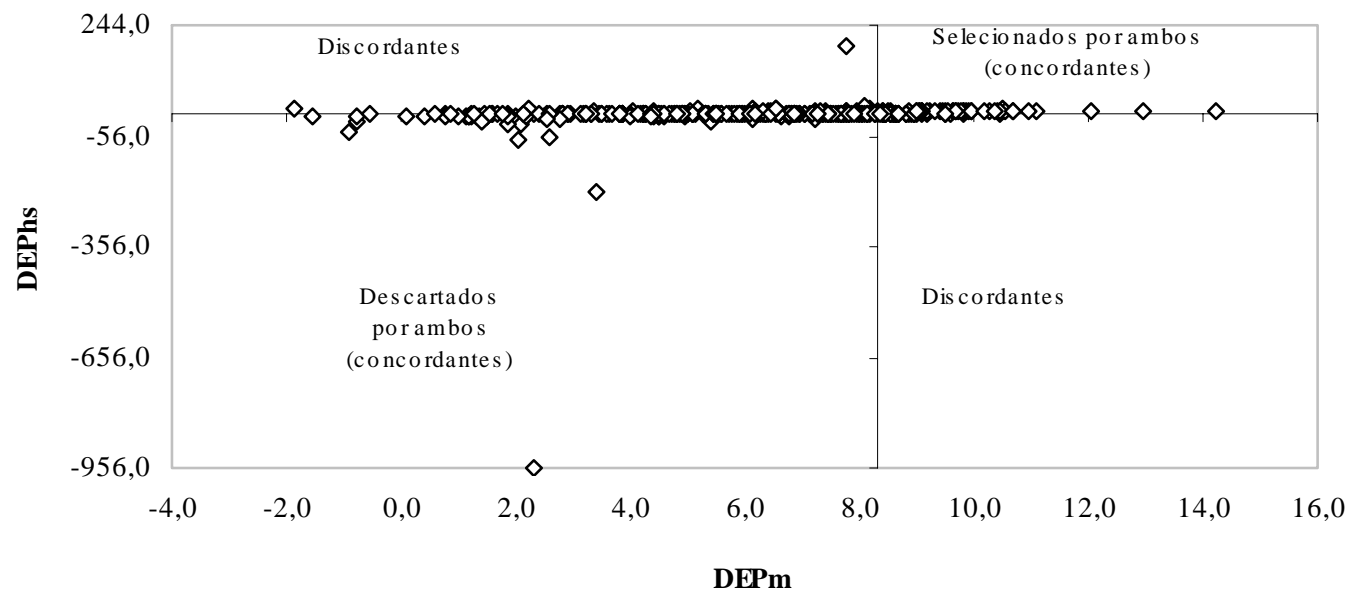

Figura 8 - Dispersões das DEPs para peso à desmama nos quadrantes definidos pelos pontos de truncamentos dos $25 \%$ melhores touros para os modelos HS (DEPhs $\geq 7,88 \mathrm{~kg})$ e $\mathrm{M}(\mathrm{DEPm} \geq 8,30 \mathrm{~kg})$. 


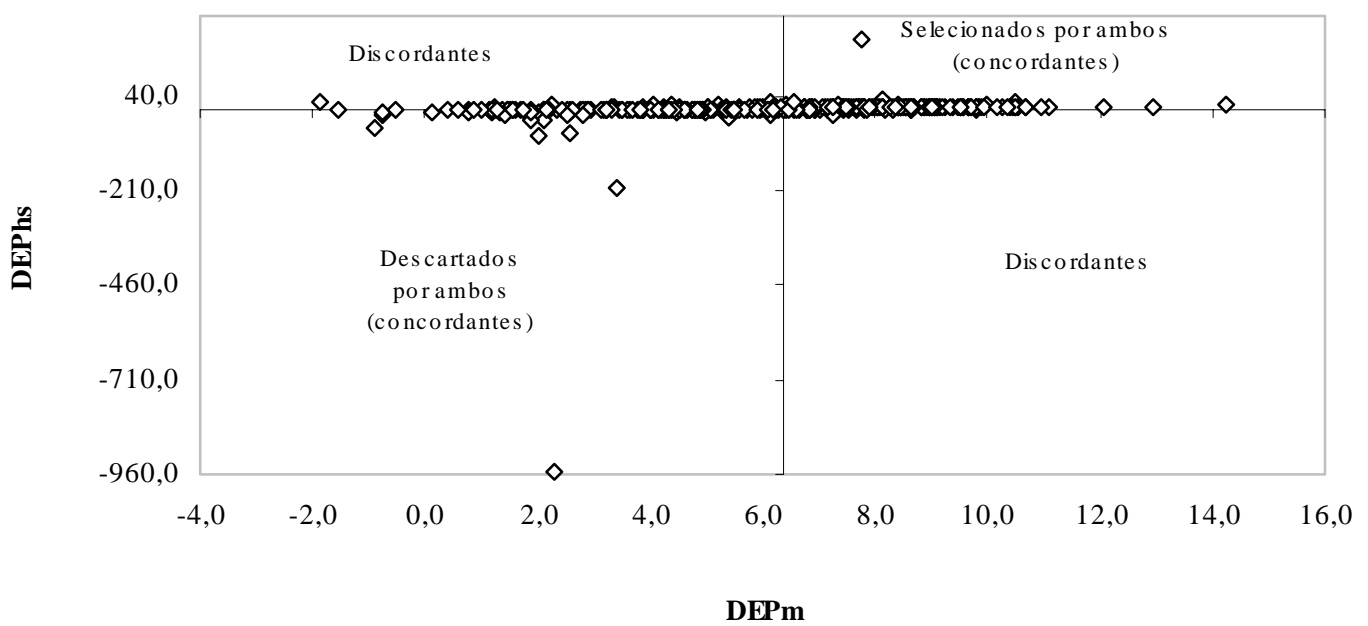

Figura 9 - Dispersões das DEPs para peso à desmama nos quadrantes definidos pelos pontos de truncamentos dos 50\% melhores touros para os modelos HS (DEPhs $\geq 5,85 \mathrm{~kg})$ e $\mathrm{M}(\mathrm{DEPm} \geq 6,37 \mathrm{~kg})$.

Para se estudar melhor a associação entre os métodos de estimação de DEPs, foram calculados os coeficientes de correlação de Pearson e de Spearman, sendo que o primeiro relaciona o valor das DEPs estimadas por dois métodos e o segundo, correlaciona as posições de rank dos touros nos métodos. Os coeficientes de correlação entre os métodos podem ser vistos na Tabela 10.

Tabela 10 - Correlações simples e de rank das DEPs dos touros obtidas a partir dos diferentes modelos HS, HK e M, para peso a desmama

\begin{tabular}{lcccccc}
\hline \multicolumn{3}{c}{ Correlação de Pearson das DEPs } & \multicolumn{3}{c}{ Correlação de Spearman (Rank) } \\
\hline & HS & HK & M & HS & HK & M \\
\hline HS & 1,00 & 0,15 & 0,15 & 1,00 & 0,77 & 0,77 \\
HK & & 1,00 & 0,99 & & 1,00 & 0,99 \\
M & & & 1,00 & & & 1,00 \\
\hline
\end{tabular}

Todas as correlações foram significativamente diferentes de zero e positivas.

Observando-se as correlações de Pearson entre os métodos M e HK, nota-se que a mesma é de alta magnitude e bem superior às outras. Porém, quando se analisa a correlação existente entre HS e M, observa-se que a mesma é de pequena magnitude, assim como a correlação existente entre HS e HK. 
Analisando-se a correlação de rank (Spearman) entre os métodos, observa-se que a correlação entre os métodos HK e M é superior às demais, indicando que há poucos touros discordantes quanto à classificação quando há comparação dos métodos HK e M. Entretanto, quando são analisados os métodos HS e M, fica evidente a discordância entre eles.

Com a observação dos gráficos e coeficientes de correlação, pode-se perceber que não há grande variação entre as classificações dos animais selecionados pelos métodos HK e M.

\subsection{Peso ao sobreano}

Para peso ao sobreano, foram utilizados dados de 45.014 animais. Na Tabela 11 está disposta a estatística descritiva das três metodologias, antes de se obter a classificação por porcentagem.

Tabela 11 - Estatística descritiva das metodologias de estimação de DEP para peso ao sobreano: média, desvio-padrão (DP), mínimo (Min) e máximo (Max)

\begin{tabular}{ccccc}
\hline & Média & DP & Min & Max \\
\hline M & 10,15 & 5,60 & $-3,27$ & 21,30 \\
HK & 309,17 & 4,02 & 300,55 & 340,45 \\
HS & 5,11 & 22,58 & $-103,24$ & 271,17 \\
\hline
\end{tabular}

Para peso ao sobreano, a constante $\mathrm{K}$ é representada pela média da característica, correspondente a $302 \mathrm{~kg}$.

Observando-se o desvio-padrão das três metodologias, verifica-se que os métodos M e HK possuem desvios bem inferiores ao método HS, sendo o método HK o de menor desvio, sugerindo que os touros selecionados por esse método apresentam menor variabilidade em sua progênie.

Nas Tabelas 12 e 13 são mostradas as médias dos touros discordantes e melhores classificados das metodologias, selecionados pelos métodos HS e $\mathrm{M}$, e para HK e $\mathrm{M}$, respectivamente, para a característica peso ao sobreano.

Comparando-se os métodos HS e M, independentemente da porcentagem, os touros selecionados pelo método $\mathrm{H}$ possuem desvios maiores que os selecionados pelo método $\mathrm{M} \mathrm{e}$ por HK, o que pode indicar maior variabilidade nos touros selecionados pelo método HS. Além disso, quando se observa as médias, fica bem evidente que os touros discordantes e 
selecionados por M possuem média de DEPs de maior magnitude que HS, apresentando assim, além de menor variabilidade, maior média, atributo requerido pelo mercado.

Verificando-se os coeficientes ligados à distribuição dos dados, nota-se que a assimetria existente é de mesma intensidade nos dois métodos, fato que não ocorre com a curtose. O método HS possui maior coeficiente de curtose em todas as porcentagens, indicando que os filhos dos touros encontram-se mais concentrados em torno do valor central, em comparação com a curva normal, dando a idéia de menor variabilidade. Porém, quando se avalia a amplitude, constata-se que o método HS a possui de maior intensidade que $\mathrm{M}$, contrariando a idéia sugerida anteriormente de menor variabilidade.

Tabela 12 - Comparação entre as metodologias HS e M, para os touros discordantes do topo da classificação para a característica peso ao sobreano

\begin{tabular}{cccccccccc}
\hline & media_ps & h_ps & dp_ps & ca & ck & max_ps & min_ps & amplitude \\
\hline & & \multicolumn{7}{c}{ TOP 10\% } \\
\hline media_HS & 9,8 & 25,2 & 5,1 & $-0,5$ & 1,0 & 21 & $-7,5$ & 30,4 \\
media M & 18,1 & 17,0 & 4,6 & $-0,5$ & 0,1 & 27,3 & 7,0 & 21,1 \\
\hline & & \multicolumn{7}{c}{ TOP 25\% } \\
\hline media_HS & 11,0 & 22,4 & 5,1 & $-0,5$ & 1,2 & 21,3 & $-5,8$ & 28,0 \\
media M & 15,2 & 13,4 & 4,1 & $-0,5$ & 0,5 & 24,8 & 1,8 & 22,8 \\
\hline & & \multicolumn{7}{c}{ TOP 50\% } \\
\hline media_HS & 7,7 & 13,0 & 4,8 & $-0,4$ & 0,5 & 19,4 & $-7,9$ & 25,9 \\
media M & 11,8 & 8,9 & 4,5 & $-0,4$ & 0,4 & 22,1 & 0,2 & 22,1 \\
\hline
\end{tabular}

media_ps: média das DEPs dos touros; h_ ps: DEP harmônica dos touros; dp_ ps: desvio-padrão; ca: coeficiente de assimetria; ck: coeficiente de curtose; max_ps: valor máximo de estimação de DEP; min_ps: valor mínimo de estimação de DEP; media_HS: média dos touros classificados pela metodologia HS; media_M: média dos touros classificados pela metodologia M.

Na comparação dos touros selecionados pelos métodos HK e M, apenas os $10 \%$ melhores touros possuem discordância entre os métodos. Percebe-se que as médias dos touros selecionados pelos métodos HK e M apresentam-se iguais. Porém, os desvios-padrão, são maiores no método $\mathrm{M}$, ainda que a diferença seja pequena.

As médias dos coeficientes de assimetria e curtose dos touros selecionados pelo método $\mathrm{M}$ são de maior magnitude quando comparados com o método $\mathrm{HK}$, o que evidencia que a curva da distribuição da progênie dos mesmos está deslocada para a direita e também com a maior parte dos dados acima da média. Porém, maior parte não significa totalidade, conservando assim a idéia de variabilidade sugerida pela magnitude do desvio-padrão. Isso pode ser melhor observado quando a amplitude é avaliada. É bem evidente que a amplitude 
referente aos touros selecionados pelo método M é superior ao método HK.

Tabela 13 - Comparação entre as metodologias HK e M, para os touros discordantes do topo da classificação para a característica peso ao sobreano

\begin{tabular}{ccccccccc}
\hline & media_ps & hk_ps & dp_ps & ca & ck & max_ps & min_ps & amplitude \\
\hline \multicolumn{7}{c}{} & & \multicolumn{7}{c}{ TOP 10\% } \\
\hline media_HK & 17,6 & 321,5 & 3,7 & $-0,2$ & $-0,1$ & 24,2 & 9,2 & 15,1 \\
media M & 17,6 & 321,5 & 5,3 & $-0,9$ & 3,2 & 32,2 & $-6,0$ & 38,2 \\
\hline
\end{tabular}

media_ps: média das DEPs dos touros; h_ ps: DEP harmônica dos touros; dp_ ps: desvio-padrão; ca: coeficiente de assimetria; ck: coeficiente de curtose; max_ps: valor máximo de estimação de DEP; min_ps: valor mínimo de estimação de DEP; media_H: média dos touros classificados pela metodologia H; media_M: média dos touros classificados pela metodologia M.

Para auxiliar na tomada de decisão por um touro ou outro, são utilizadas as acurácias das DEPs, as quais podem dar mais confiança da predição das DEPs. As acurácias obtidas para as DEPs dos touros selecionados por cada um dos métodos pode ser visualizada na Tabela 14.

Tabela 14 - Média das acurácias dos touros discordantes e selecionados por cada um dos métodos para peso ao sobreano

\begin{tabular}{cccc}
\hline & Top 10\% & Top 25\% & Top 50\% \\
\hline M & 0,64 & 0,65 & 0,66 \\
HK & 0,64 & 0,65 & 0,66 \\
HS & 0,69 & 0,67 & 0,67 \\
\hline
\end{tabular}

Observando-se a Tabela 14, nota-se que a acurácia das DEPs referentes as estimativas realizadas pelo método HS são levemente superiores às demais, mas com muito pouca intensidade. Assim como acontece com peso à desmama, torna-se um pouco inviável a escolha de um ou outro método de acordo com as acurácias, já que as mesmas estão muito próximas.

As taxas de discordância dispostas na Tabela 15, podem ser visualizadas nas Figuras 10, 11 e 12, entre os métodos HK e M, e nas Figuras 13, 14 e 15 para os métodos HS e M. Observa-se que as taxas referentes aos métodos HS e M são bem superiores às do HK e M, chegando a ser inexistente para os 25 e 50\% discordantes entre HK e M. 
Tabela 15 - Taxa de discordância (\%) entre os touros das metodologias HS e HK em comparação com M para peso ao sobreano

\begin{tabular}{cccc} 
& \multicolumn{3}{c}{ TOP } \\
\cline { 2 - 4 } & $\mathbf{1 0 \%}$ & $\mathbf{2 5 \%}$ & $\mathbf{5 0 \%}$ \\
\hline $\begin{array}{c}\text { media_HS } \\
\text { media M }\end{array}$ & 54 & 28 & 16 \\
\hline & $\mathbf{1 0 \%}$ & $\mathbf{2 5 \%}$ & $\mathbf{5 0 \%}$ \\
\hline media_HK & & 0 & 0
\end{tabular}

Top: touros do topo da classificação; media_HS: média dos touros classificados pela metodologia HS; media_HK: média dos touros classificados pela metodologia HK; media_M: média dos touros classificados pela metodologia $\mathrm{M}$.

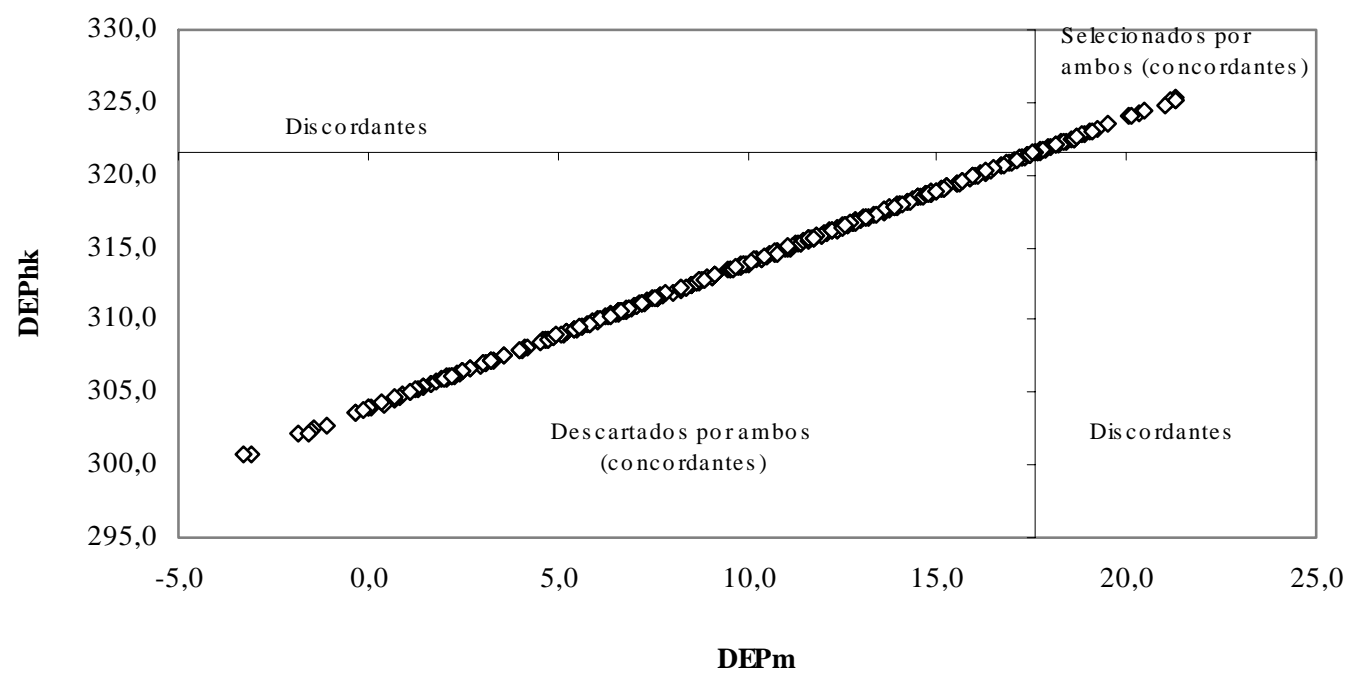

Figura 10 - Dispersões das DEPs para peso ao sobreano nos quadrantes definidos pelos pontos de truncamentos dos $10 \%$ melhores touros para os modelos

HK (DEPhk $\geq 321,5 \mathrm{~kg})$ e M (DEPm $\geq 17,56 \mathrm{~kg})$. 


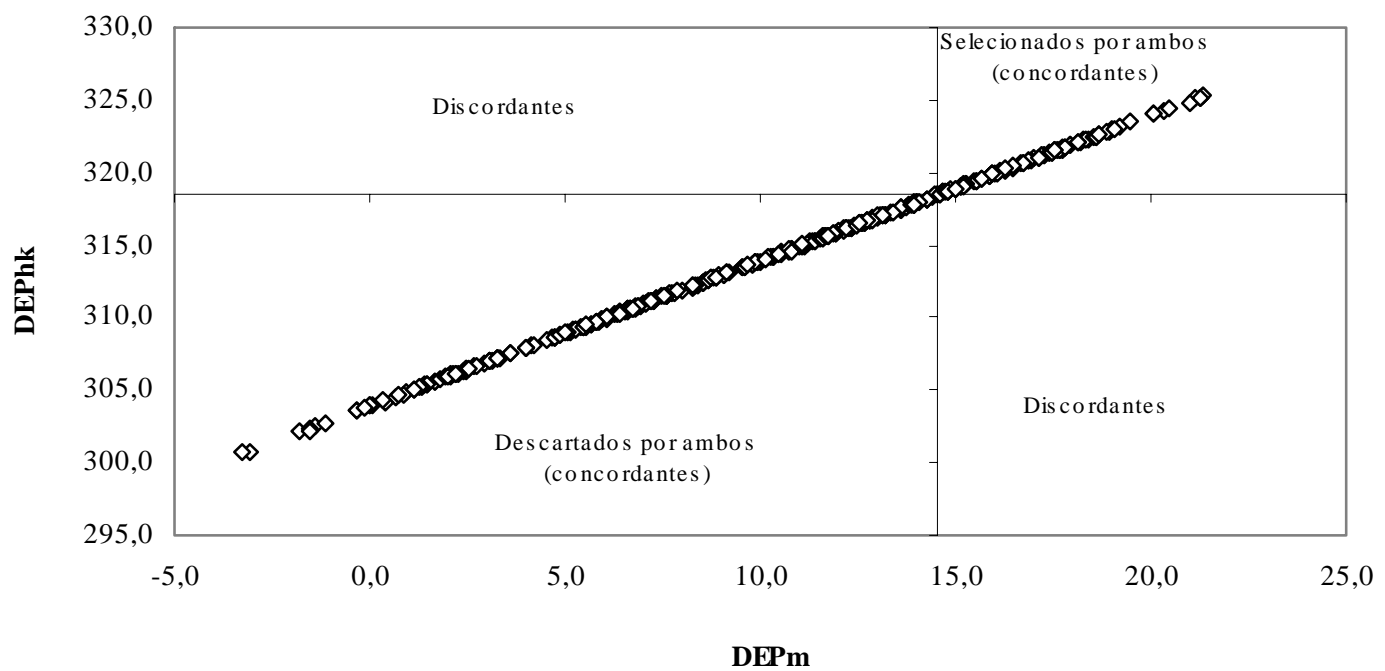

Figura 11 - Dispersões das DEPs para peso ao sobreano nos quadrantes definidos pelos pontos de truncamentos dos 25\% melhores touros para os modelos HK (DEPhk $\geq 318,48 \mathrm{~kg})$ e M (DEPm $\geq 14,52 \mathrm{~kg})$.

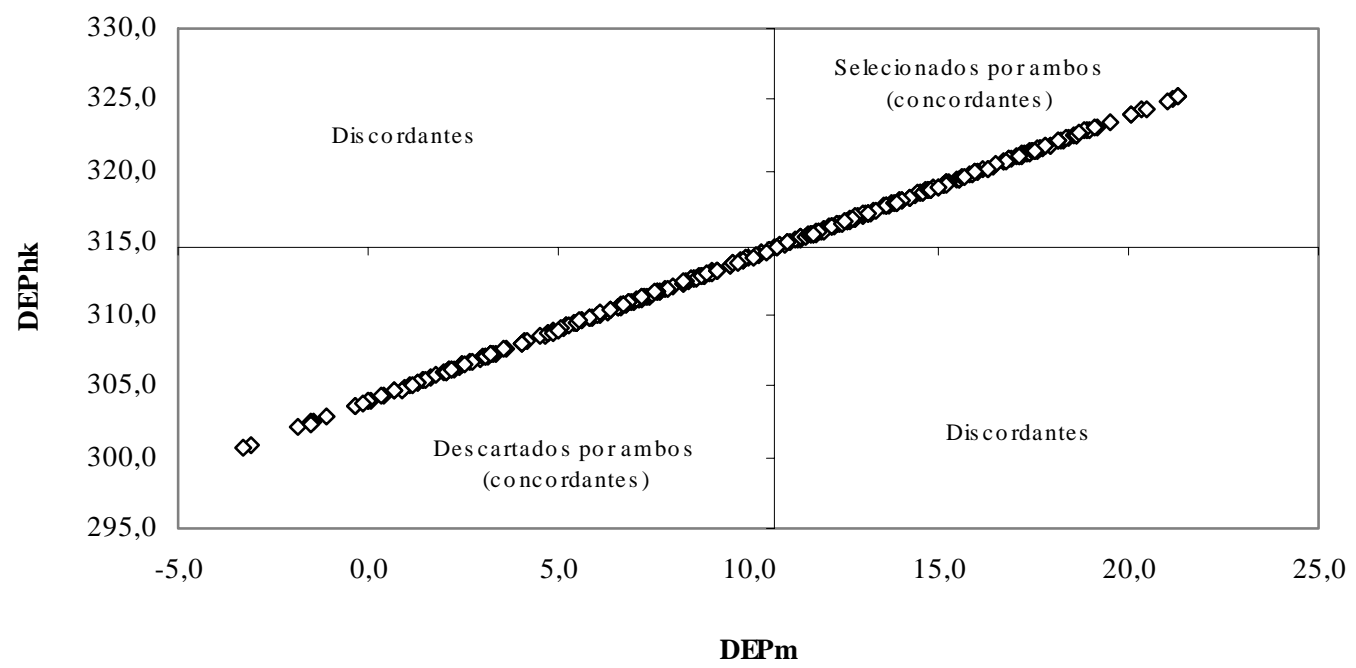

Figura 12 - Dispersões das DEPs para peso ao sobreano nos quadrantes definidos pelos pontos de truncamentos dos 50\% melhores touros para os modelos HK (DEPhk $\geq 314,62 \mathrm{~kg})$ e M (DEPm $\geq 10,71 \mathrm{~kg})$. 


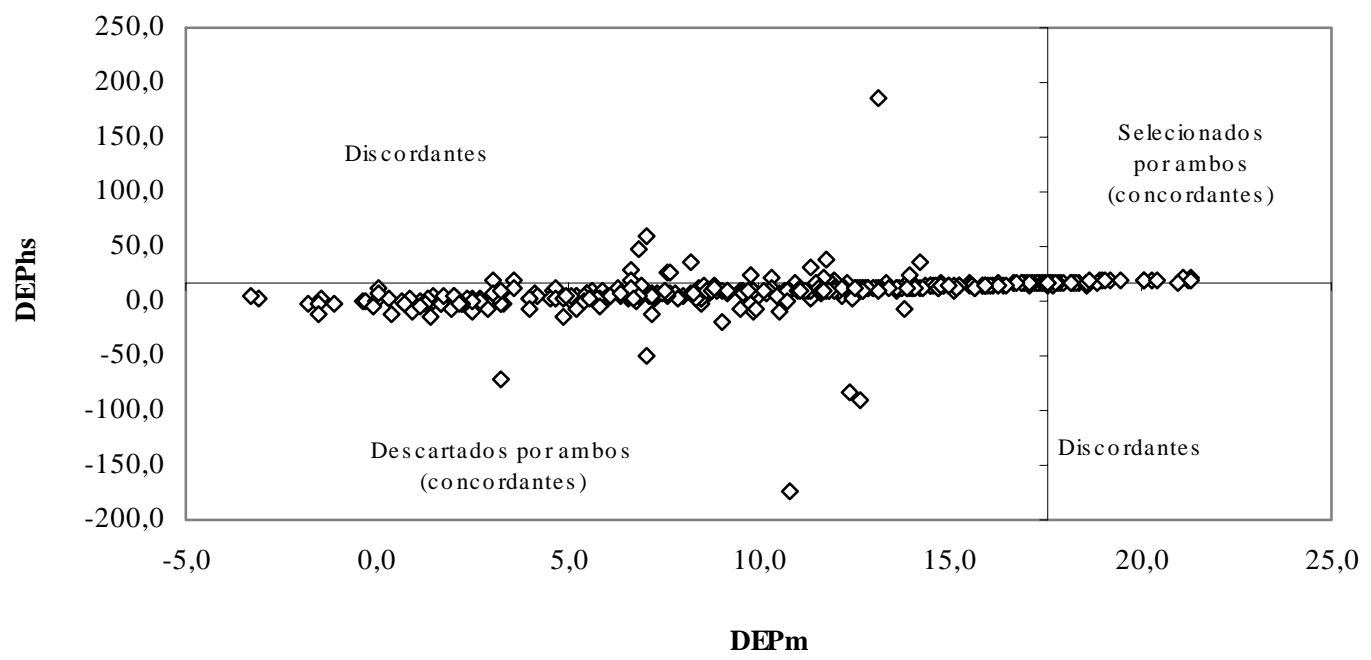

Figura 13 - Dispersões das DEPs para peso ao sobreano nos quadrantes definidos pelos pontos de truncamentos dos 10\% melhores touros para os modelos

HS (DEPhs $\geq 17,76 \mathrm{~kg})$ e $\mathrm{M}(\mathrm{DEPm} \geq 17,55 \mathrm{~kg})$.

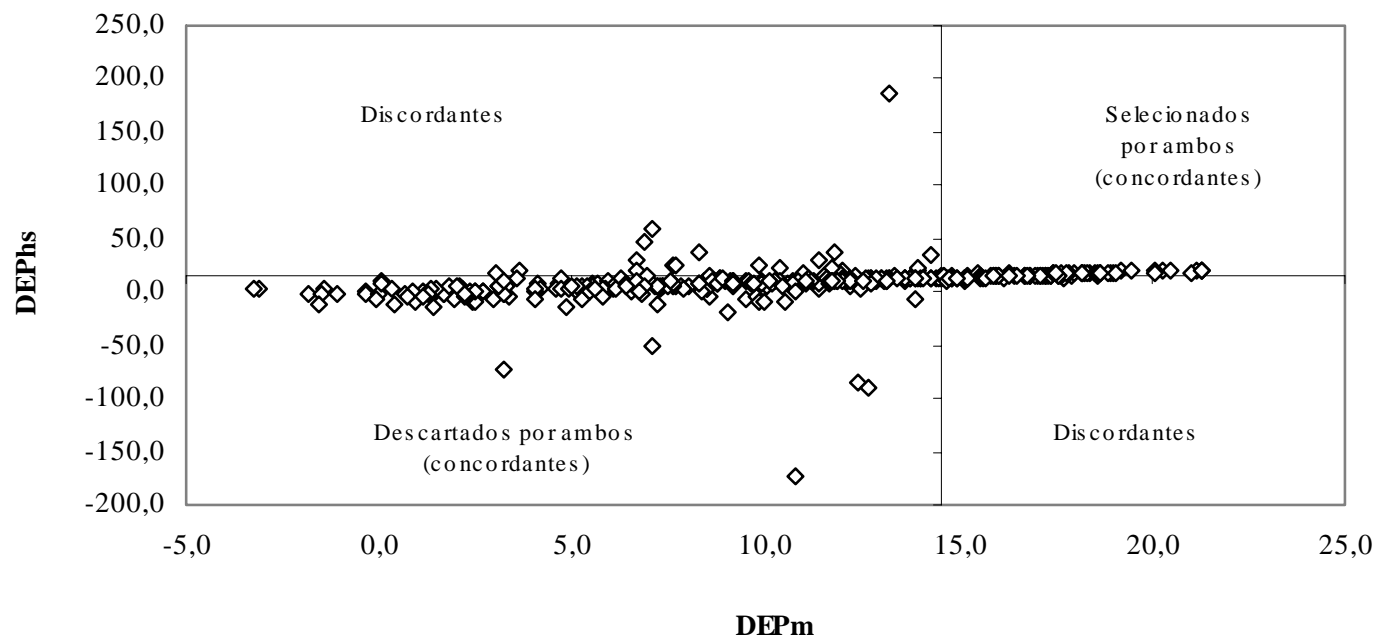

Figura 14 - Dispersões das DEPs para peso ao sobreano nos quadrantes definidos pelos pontos de truncamentos dos 25\% melhores touros para os modelos

$$
\text { HS (DEPhs } \geq 14,63 \mathrm{~kg}) \text { e } \mathrm{M}(\mathrm{DEPm} \geq 14,52 \mathrm{~kg}) \text {. }
$$




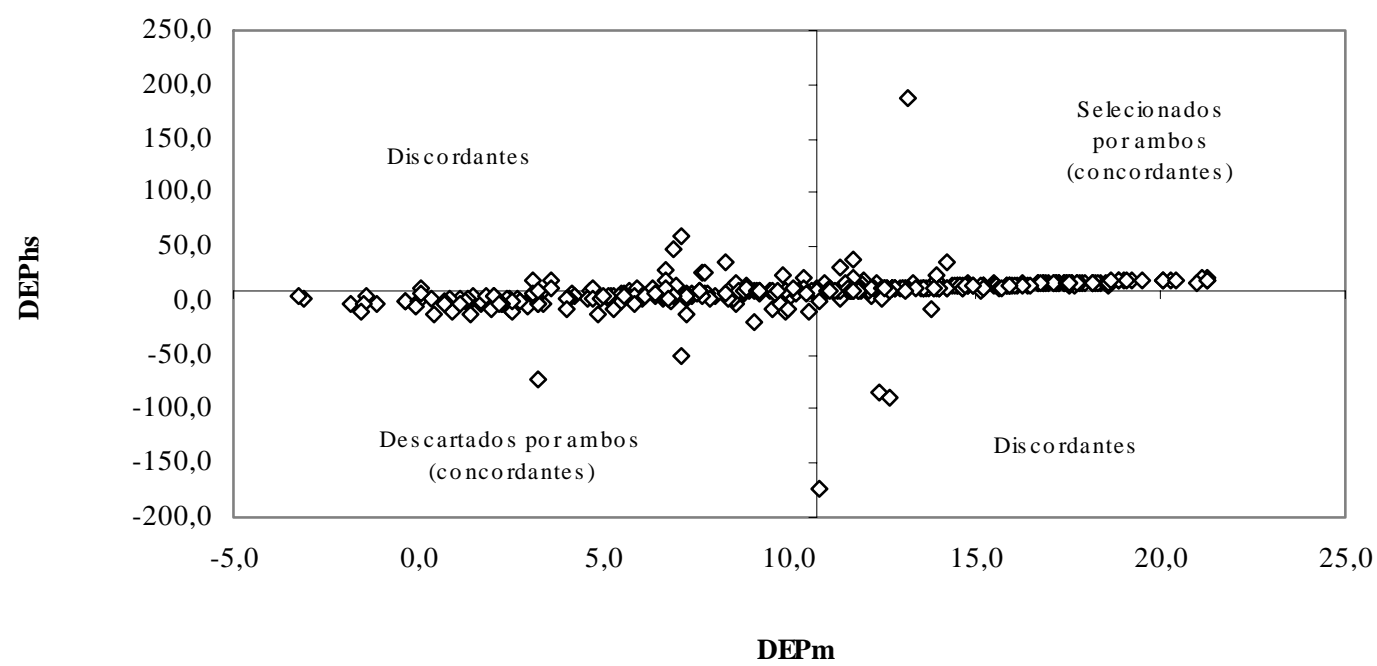

Figura 15 - Dispersões das DEPs para peso ao sobreano nos quadrantes definidos pelos pontos de truncamentos dos 50\% melhores touros para os modelos HS (DEPhs $\geq 10,26 \mathrm{~kg})$ e $M(\mathrm{DEPm} \geq 10,71 \mathrm{~kg})$.

Verificando-se a estatística descritiva dos touros menos privilegiados na classificação, contidos nas Tabelas 16 e 17, nota-se que a média é maior tanto para HS quanto para HK quando comparado com o método $\mathrm{M}$. Porém os desvios têm comportamento diferente: enquanto no método HS eles apresentam-se de menor magnitude que o método $\mathrm{M}$, o método HK proporciona maiores desvios em relação ao M, exceto para os $10 \%$.

Tabela 16 - Comparação entre as metodologias HS e M, para os touros do final da classificação para a característica peso ao sobreano

\begin{tabular}{|c|c|c|c|c|c|c|c|c|}
\hline & media_ps & h_ps & dp_ps & ca & ck & max_ps & min_ps & amplitude \\
\hline & \multicolumn{8}{|c|}{ BOT $10 \%$} \\
\hline media_HS & 7,2 & $-8,2$ & 4,7 & $-0,3$ & 0,8 & 19,8 & $-6,3$ & 25,4 \\
\hline \multirow[t]{2}{*}{ media M } & 0,9 & 1,6 & 5,0 & 0,0 & 2,0 & 14 & $-9,0$ & 23,0 \\
\hline & \multicolumn{8}{|c|}{ BOT 25\% } \\
\hline media_HS & 8,5 & $-0,7$ & 4,5 & $-0,4$ & 0,6 & 19,7 & $-3,8$ & 24,2 \\
\hline \multirow[t]{2}{*}{ media $\mathbf{M}$} & 4,4 & 6,4 & 4,6 & $-0,1$ & 0,9 & 15,3 & $-8,1$ & 22,8 \\
\hline & \multicolumn{8}{|c|}{ BOT $50 \%$} \\
\hline media_HS & 11,8 & 8,8 & 4,4 & $-0,4$ & 0,4 & 22,1 & 0,2 & 22,2 \\
\hline media M & 7,7 & 13,0 & 4,8 & $-0,4$ & 0,5 & 19,4 & $-7,9$ & 25,8 \\
\hline
\end{tabular}


Tabela 17 - Comparação entre as metodologias HK e M, para os touros discordantes do final da classificação para a característica peso ao sobreano

\begin{tabular}{|c|c|c|c|c|c|c|c|c|}
\hline & media_ps & hk_ps & dp_ps & ca & ck & max_ps & min_ps & amplitude \\
\hline & \multicolumn{8}{|c|}{ BOT $10 \%$} \\
\hline media_HK & 4,1 & 303,5 & $-3,1$ & 5,3 & 0,1 & 0,5 & 14,0 & 19,4 \\
\hline \multirow[t]{2}{*}{ media $\mathbf{M}$} & 0,7 & 307,8 & $-2,2$ & 2,0 & 0,6 & 2,3 & 14,0 & 23,6 \\
\hline & \multicolumn{8}{|c|}{ BOT 25\% } \\
\hline media_HK & 7,8 & 305,7 & 5,0 & 9,0 & $-0,1$ & 0,5 & 17,3 & 20,0 \\
\hline \multirow[t]{2}{*}{ media $\mathbf{M}$} & 3,6 & 310,8 & 1,7 & 4,8 & $-0,2$ & 2,3 & 15,7 & 26,6 \\
\hline & \multicolumn{8}{|c|}{ BOT $50 \%$} \\
\hline media_HK & 12,5 & 308,1 & 7,2 & 13,7 & $-0,4$ & 0,7 & 21,7 & 21,3 \\
\hline media M & 6,6 & 313,3 & 1,2 & 7,7 & $-0,3$ & 1,8 & 18,7 & 27,7 \\
\hline
\end{tabular}

Quando se passa a avaliar a estatística descritiva da distribuição, utilizando-se dos coeficientes de assimetria e curtose, percebe-se que ainda que de pequena magnitude, o coeficiente de assimetria do método HS é negativo, fato que não ocorre no método HK, ficando evidente que há maior concentração dos dados abaixo da média para HK. Analisandose a curtose, verifica-se que para os $10 \%$ menos privilegiados, as curvas são levemente leptocúrticas, tanto para HS quanto para HK. Para os 25 e 50\%, as curvas são consideradas ligeiramente platicúrticas para os dois métodos. Porém, nota-se que os coeficientes relacionados ao método $\mathrm{M}$ quando comparados com os do HS, apresentam-se maiores, indicando que os dados da distribuição de M estão mais próximos do valor central.

Assim como para peso à desmama, a taxa de touros discordantes entre os métodos HS e $M$ vai decrescendo à medida que a porcentagem selecionada aumenta, como visto na Tabela 18. Porém, quando observamos a taxa em relação à discordância dos métodos HK e $M$, notase que para 10 e $25 \%$, as taxas são muito pequenas, chegando a ser nula para os $50 \%$. 
Tabela 18 - Taxa de discordância (\%) entre os touros das metodologias HK e HS em comparação com M, para peso ao sobreano

\begin{tabular}{|c|c|c|c|}
\hline & \multicolumn{3}{|c|}{ BOT } \\
\hline & $10 \%$ & $25 \%$ & $50 \%$ \\
\hline \multicolumn{4}{|l|}{ media_HS } \\
\hline \multirow[t]{3}{*}{ media_M } & 67 & 30 & 15 \\
\hline & \multicolumn{3}{|c|}{ BOT } \\
\hline & $10 \%$ & $25 \%$ & $50 \%$ \\
\hline \multicolumn{4}{|l|}{ media_HK } \\
\hline media_M & 3 & 1 & 0 \\
\hline
\end{tabular}

Assim como ocorre com as correlações referente ao peso à desmama, o método HS se difere bastante dos demais. Porém, as correlações de Pearson envolvendo o método HS estão um pouco maiores para peso ao sobreano que para as demais características, mas ainda assim é considerado baixo.

Já na correlação de rank, nota-se que há muitos touros discordantes quanto a classificação quando são comparados os métodos HK e M com o método HS. Porém, quando se observa o coeficiente de correlação de Spearman entre os métodos HK e M, percebe-se que o mesmo é de grande magnitude, implicando na quase totalidade de touros concordantes.

Na Tabela 19, encontram-se os coeficientes de correlação existente entre as metodologias propostas.

Tabela 19 - Correlações simples e de rank das DEPs dos touros obtidas a partir dos diferentes modelos HS, HK e M, para peso ao sobreano

\begin{tabular}{lcccccc}
\hline \multicolumn{3}{c}{ Correlação de Pearson das DEPs } & \multicolumn{4}{c}{ Correlação de Spearman (Rank) } \\
\hline & HS & HK & M & HS & HK & M \\
\hline HS & 1,00 & 0,31 & 0,31 & 1,00 & 0,77 & 0,77 \\
HK & & 1,00 & 0,99 & & 1,00 & 0,99 \\
M & & & 1,00 & & & 1,00 \\
\hline
\end{tabular}

As correlações existentes entre os métodos HK e M são extremamente fortes, 
sugerindo que as duas metodologias fornecem praticamente a mesma classificação de touros, quanto à característica peso ao sobreano.

\subsection{Ganho de peso da desmama ao sobreano}

Para o cálculo das estimativas de DEP de ganho de peso da desmama ao sobreano foram considerados 45.014 animais. Na Tabela 20 está disposta a estatística descritiva para as diferentes metodologias propostas.

Tabela 20 - Estatística descritiva das metodologias de estimação de DEP para ganho de peso da desmama ao sobreano: média, desvio-padrão (DP), mínimo (Min) e máximo (Max)

\begin{tabular}{ccccc}
\hline & Média & DP & Min & Max \\
\hline M & 4,15 & 3,33 & $-4,96$ & 13,30 \\
HK & 119,07 & 3,34 & 109,79 & 128,24 \\
HS & 5,10 & 22,55 & $-101,50$ & 271,17 \\
\hline
\end{tabular}

Analisando-se a classificação no rank quanto à característica ganho de peso, nota-se que em sua maioria, não há touros discordantes entre as metodologias $\mathrm{M}$ e HK, com exceção apenas para os touros top nas três porcentagens de seleção, nas quais há ocorrência de apenas um touro discordante em cada categoria, como pode ser ilustrado pelas Figuras 16, 17 e 18. Para touros no final da classificação, não há presença de discordantes em nenhuma das porcentagens analisadas. 


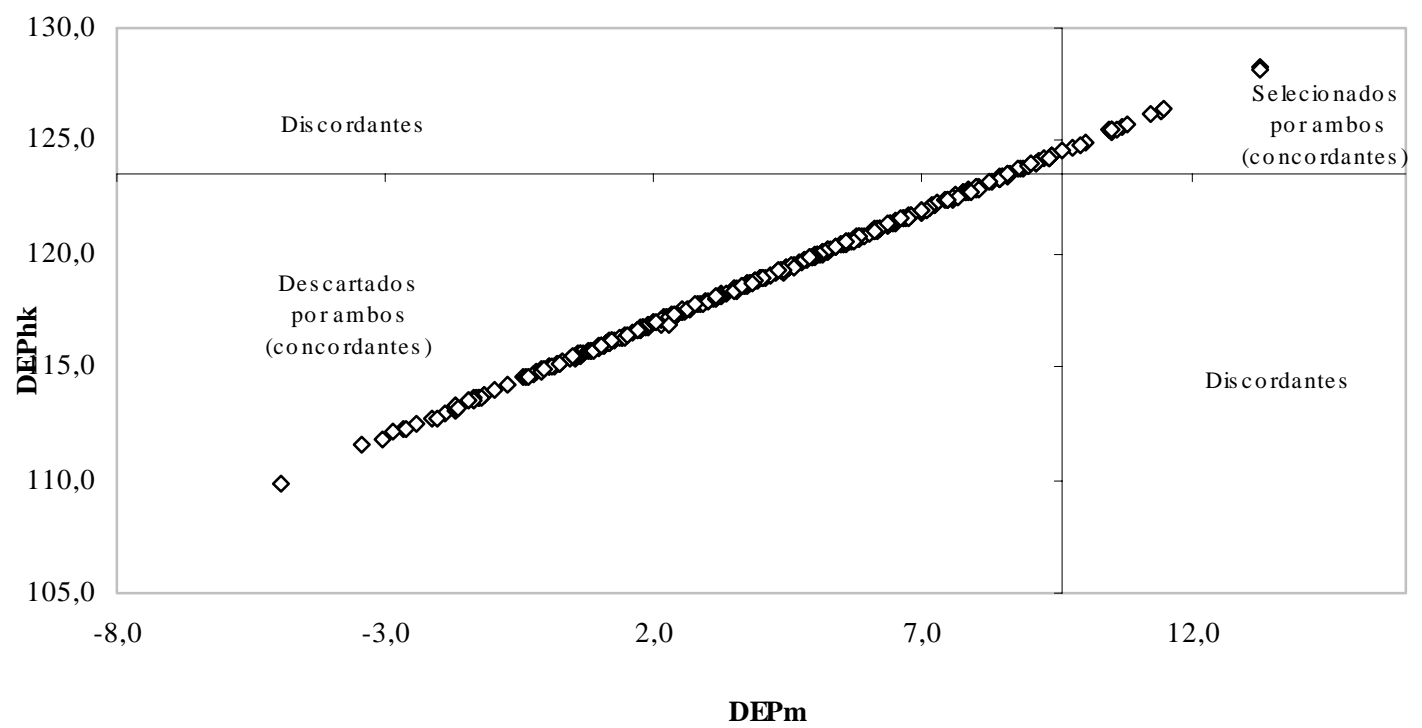

Figura 16 - Dispersões das DEPs para ganho de peso da desmama ao sobreano nos quadrantes definidos pelos pontos de truncamentos dos 10\% melhores touros para os modelos HK (DEPhk $\geq 123,53 \mathrm{~kg})$ e $\mathrm{M}(\mathrm{DEPm} \geq 8,60 \mathrm{~kg})$.

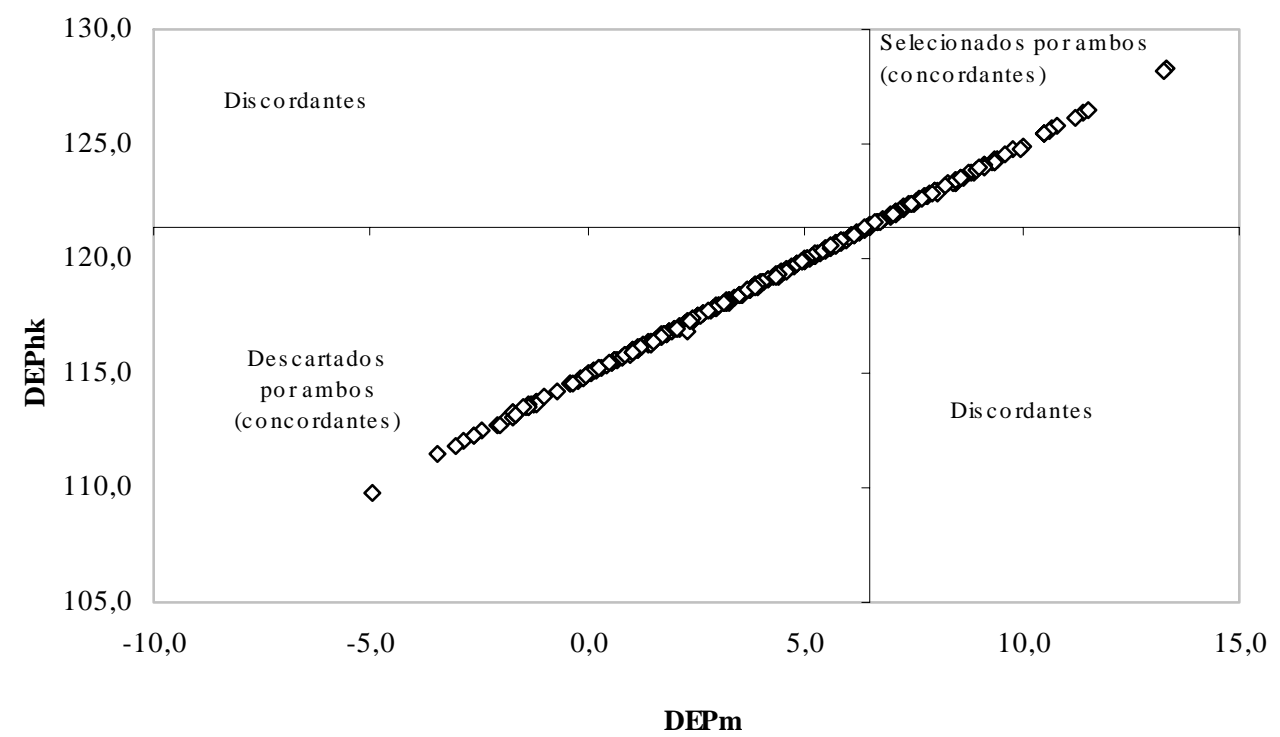

Figura 17 - Dispersões das DEPs para ganho de peso da desmama ao sobreano nos quadrantes definidos pelos pontos de truncamentos dos $25 \%$ melhores touros para os modelos HK (DEPhk $\geq 121,42 \mathrm{~kg})$ e $\mathrm{M}(\mathrm{DEPm} \geq 6,49 \mathrm{~kg})$. 


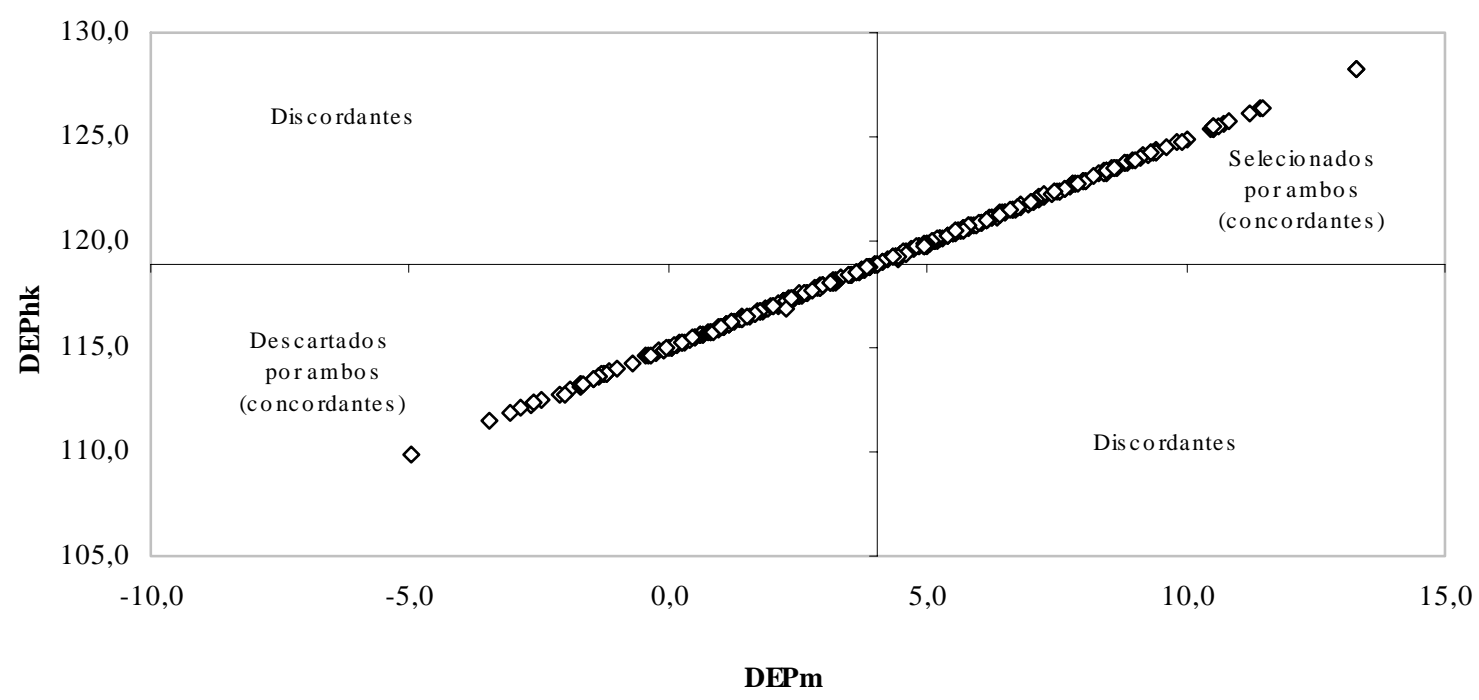

Figura 18 - Dispersões das DEPs para ganho de peso da desmama ao sobreano nos quadrantes definidos pelos pontos de truncamentos dos 50\% melhores touros para os modelos HK (DEPhk $\geq 118,99 \mathrm{~kg})$ e M (DEPm $\geq 4,05 \mathrm{~kg})$.

Quando se observa os touros discordantes nos métodos M e HS, nas Tabelas 21 e 23, observa-se que os touros selecionados pelo método M possuem médias de DEP superiores aos selecionados pelo método HS. Quando se analisa os desvios-padrão das três porcentagens de seleção, verifica-se que são exatamente da mesma magnitude para os dois métodos em questão.

Verificando-se o coeficiente de assimetria, nota-se que à medida que a porcentagem de seleção de touros top aumenta, o coeficiente de assimetria para o método HS diminui, porém, isso ocorre com baixa intensidade. Os touros discordantes e selecionados pelo método M apresentam-se de forma simétrica quando analisados os $10 \%$ melhores. Porém, ainda no método $\mathrm{M}$, quando se analisa os 25 e $50 \%$, observa-se que os coeficientes possuem mesma magnitude. Já quando é observado o coeficiente de curtose, evidencia-se, de acordo com a Tabela 21, que para os 10 e $25 \%$ melhores touros, os touros selecionados pelo método $\mathrm{M}$ possuem curtose de maior magnitude, o que nos 50\% é visualizado no método HS. Isso indica que o método M, para os 10 e $25 \%$ apresenta maior concentração de resultados, sugerindo assim, menor variabilidade dos filhos desses touros.

Inferindo-se pela amplitude dos dados, fica evidente que o método HS possui maior amplitude que o método $\mathrm{M}$, com exceção apenas para os 10\%, no qual a amplitude dos métodos é igual. Porém, segundo FERREIRA (2005), a amplitude é uma estimativa pobre e 
ineficiente, uma vez que considera os valores extremos sem informar como está a distribuição dos dados.

Tabela 21 - Comparação entre as metodologias HS e M, para os touros discordantes do topo da classificação para a característica ganho de peso da desmama ao sobreano

\begin{tabular}{cccccccccc}
\hline & media_gp & h_gp & dp_gp & ca & ck & max_gp & min_gp & amplitude \\
\hline \multicolumn{7}{c}{} & \multicolumn{7}{c}{ TOP 10\% } \\
\hline media_HS & 3,6 & 41,5 & 3,0 & $-0,1$ & 0,6 & 11,8 & $-4,1$ & 15,8 \\
media M & 9,8 & 8,7 & 3,0 & 0,0 & 1,3 & 17,2 & 1,4 & 15,8 \\
\hline \multicolumn{7}{c}{} & \multicolumn{7}{c}{ TOP 25\% } \\
\hline media_HS & 3,3 & 28,5 & 3,0 & $-0,2$ & 0,6 & 11,3 & $-5,2$ & 16,5 \\
media M & 7,5 & 4,9 & 3,0 & $-0,2$ & 1,0 & 15,0 & $-0,8$ & 15,7 \\
\hline & & \multicolumn{7}{c}{ TOP 50\% } \\
\hline media_HS & 2,1 & 18,4 & 3,1 & $-0,3$ & 1,8 & 9,9 & $-8,0$ & 17,9 \\
media M & 5,2 & 0,4 & 3,1 & $-0,2$ & 0,8 & 12,8 & $-3,2$ & 16,0 \\
\hline
\end{tabular}

media_gp: média das DEPs dos touros; h_gp: DEP harmônica dos touros; dp_ gp: desvio-padrão; ca: coeficiente de assimetria; ck: coeficiente de curtose; max_ gp: valor máximo de estimação de DEP; min_ gp: valor mínimo de estimação de DEP; media_HS: média dos touros classificados pela metodologia HS; media_M: média dos touros classificados pela metodologia M.

Para dar maior confiabilidade na estimação das DEPs, foi calculada a média das acurácias dos touros discordantes e selecionados por cada um dos métodos, dispostas na Tabela 22.

Assim como nas outras características, as acurácias das DEPs dos touros para ganho de peso da desmama ao sobreano também encontram-se bem próximas, tanto para os diferentes métodos de estimação de DEPs, como para a porcentagem de touros selecionadas, inviabilizando a comparação dos métodos através dela.

Tabela 22 - Média das acurácias dos touros discordantes e selecionados por cada um dos métodos para ganho de peso da desmama ao sobreano

\begin{tabular}{cccc}
\hline & Top 10\% & Top 25\% & Top 50\% \\
\hline M & 0,60 & 0,61 & 0,61 \\
HK & 0,60 & 0,61 & 0,61 \\
H & 0,59 & 0,61 & 0,61 \\
\hline
\end{tabular}

Analisando-se os touros menos privilegiados na classificação, fica evidente que ao contrário do que acontece com os touros do topo, o método $M$ apresenta menores médias da 
estimação de DEPs que o método HS, sendo a média referente aos 10\%, negativa.

Os desvios-padrão assim como ocorre nos touros top, também se encontram similares entre os dois métodos.

Entretanto, ao contrário do que acontece com os touros do ápice, o coeficiente de assimetria para os $10 \%$ touros menos privilegiados diminui à medida que a porcentagem de classificação aumenta, porém isso ocorre no método M. O método HS possui distribuição simétrica para os 25\%. Analisando-se a curtose, nota-se que nos $10 \%$ o coeficiente se apresenta maior no método $\mathrm{M}$, enquanto que nos 25 e 50\% o coeficiente é maior para o método M. Porém, para os touros menos privilegiados é favorável que a amplitude seja maior, o que indica que os touros do topo a possuem de menor intensidade.

Tabela 23 - Comparação entre as metodologias HS e M, para os touros discordantes do final da classificação para a característica ganho de peso da desmama ao sobreano

\begin{tabular}{|c|c|c|c|c|c|c|c|c|}
\hline & media_gp & h_gp & dp_gp & ca & ck & max_gp & min_gp & amplitude \\
\hline & \multicolumn{8}{|c|}{ BOT $10 \%$} \\
\hline media_HS & 2,7 & $-15,7$ & 3,0 & $-0,3$ & 1,7 & 9,9 & $-6,6$ & 16,5 \\
\hline \multirow[t]{2}{*}{ media $\mathbf{M}$} & $-1,5$ & $-0,2$ & 3,0 & 0,1 & 1,5 & 6,3 & $-9,2$ & 15,5 \\
\hline & \multicolumn{8}{|c|}{ BOT 25\% } \\
\hline media_HS & 3,8 & $-6,3$ & 2,9 & 0,0 & 0,3 & 10,8 & $-3,4$ & 14,2 \\
\hline \multirow[t]{2}{*}{ media M } & 0,7 & 5,7 & 3,0 & $-0,2$ & 1,9 & 8,9 & $-8,9$ & 17,8 \\
\hline & \multicolumn{8}{|c|}{ BOT 50\% } \\
\hline media_HS & 5,2 & 0,4 & 3,1 & $-0,2$ & 0,8 & 12,8 & $-3,2$ & 16,0 \\
\hline media M & 2,1 & 18,4 & 3,1 & $-0,3$ & 1,8 & 9,9 & $-8,0$ & 17,9 \\
\hline
\end{tabular}

Tabela 24 - Taxa de discordância (\%) entre os touros das metodologias HS e M para ganho de peso da desmama ao sobreano

\begin{tabular}{|c|c|c|c|}
\hline & \multicolumn{3}{|c|}{ TOP } \\
\hline & $10 \%$ & $25 \%$ & $50 \%$ \\
\hline \multicolumn{4}{|l|}{ media_HS } \\
\hline \multirow[t]{3}{*}{ media M } & 69 & 45 & 28 \\
\hline & \multicolumn{3}{|c|}{ BOT } \\
\hline & $10 \%$ & $25 \%$ & $50 \%$ \\
\hline \multicolumn{4}{|l|}{ media_HS } \\
\hline media M & 72 & 38 & 28 \\
\hline
\end{tabular}


metodologia HS; media_M: média dos touros classificados pela metodologia $\mathrm{M}$.

A taxa de discordância diminui significativamente à medida que a porcentagem de classificação aumenta. Esse fato pode ser explicado pela proximidade de valores entre as estimativas dos touros à medida que a porcentagem é ampliada, como pôde ser visualizado na Tabela 24, e pode ser ilustrado nas Figuras 19, 20 e 21.

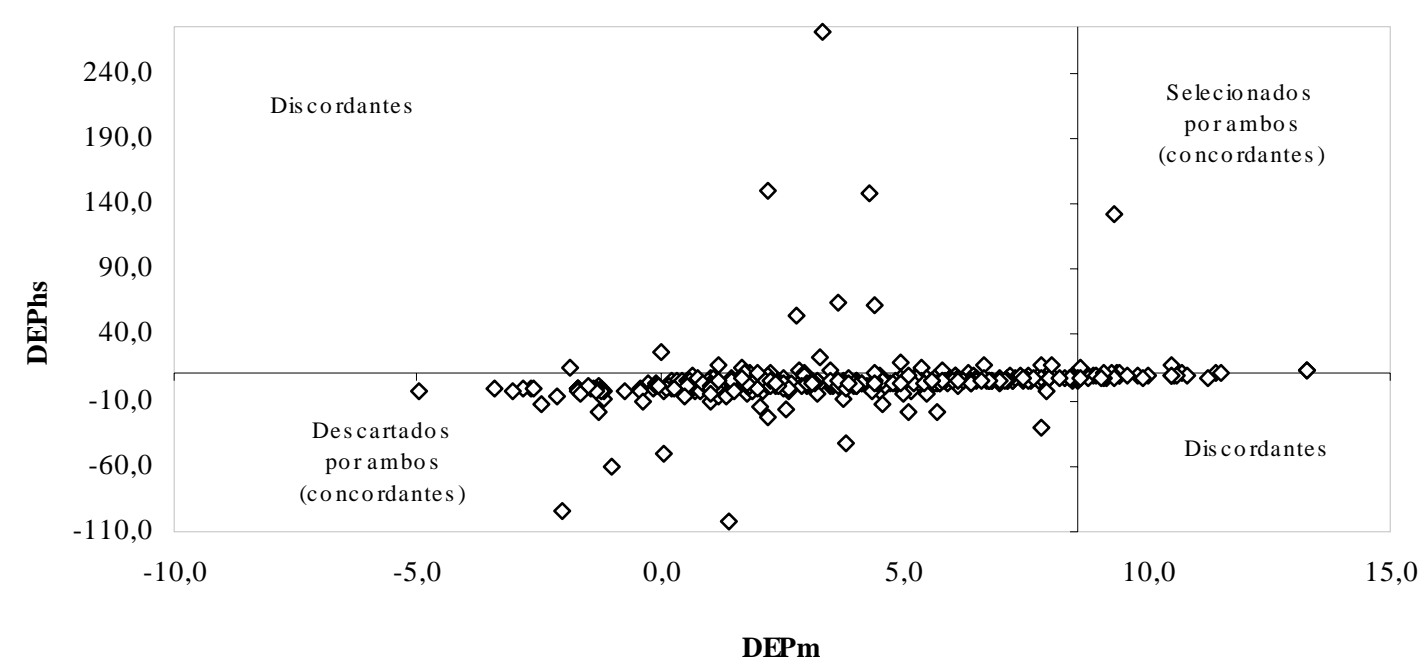

Figura 19 - Dispersões das DEPs para ganho de peso da desmama ao sobreano nos quadrantes definidos pelos pontos de truncamentos dos 10\% melhores touros para os modelos HS (DEPhs $\geq 10,26 \mathrm{~kg})$ e $M(\mathrm{DEPm} \geq 8,60 \mathrm{~kg})$.

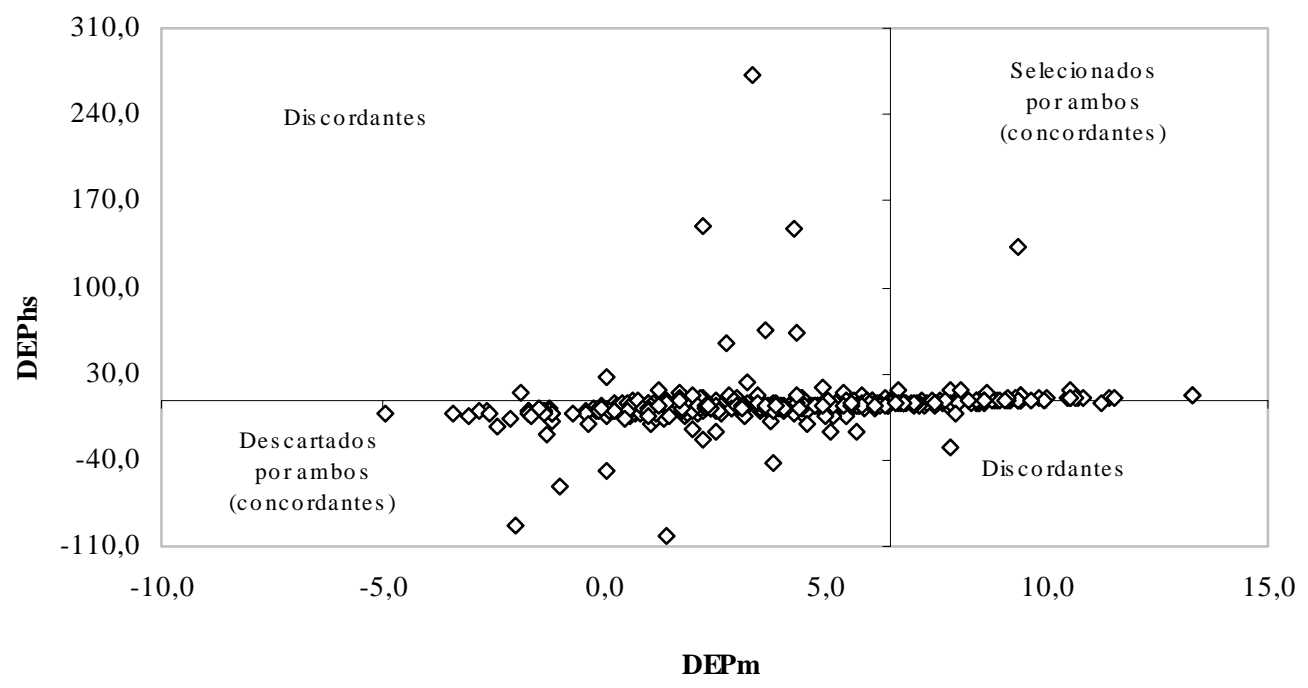

Figura 20 - Dispersões das DEPs para peso ao sobreano nos quadrantes definidos pelos pontos de truncamentos dos 25\% melhores touros para os modelos HS (DEPhs $\geq 7,29 \mathrm{~kg})$ e $M(\mathrm{DEPm} \geq 6,49 \mathrm{~kg})$. 


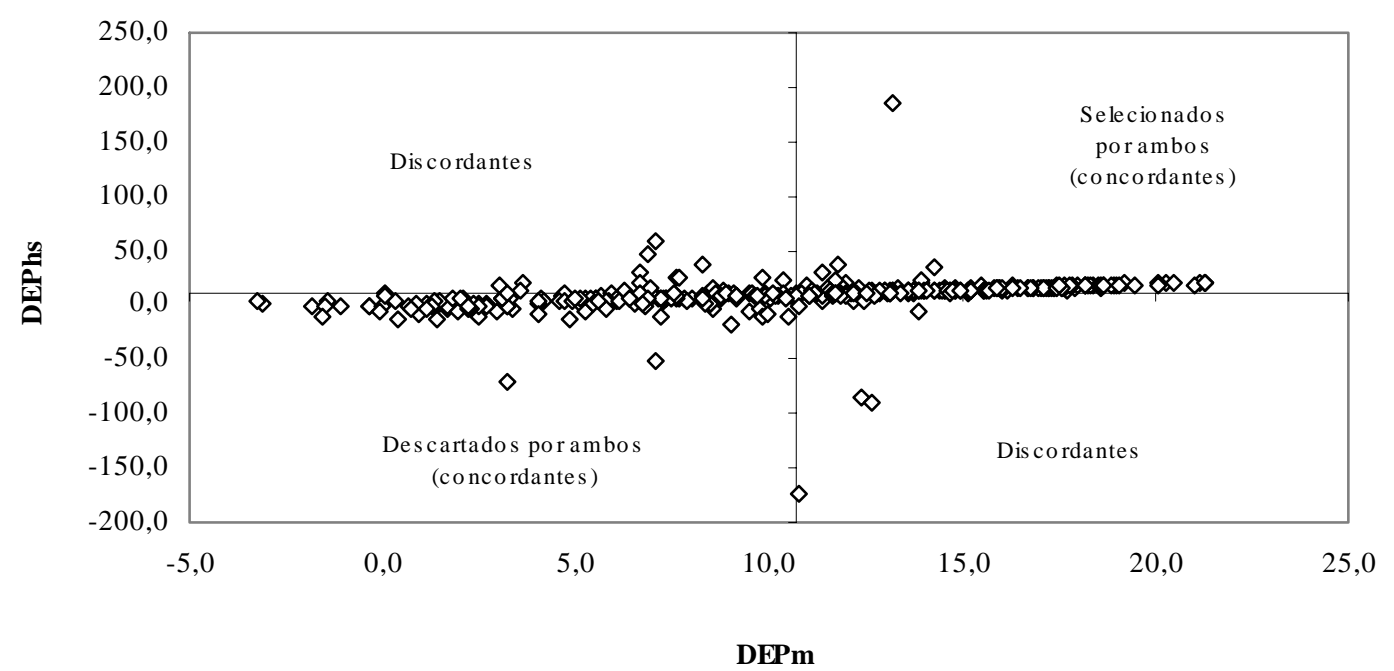

Figura 21 - Dispersões das DEPs para peso ao sobreano nos quadrantes definidos pelos pontos de truncamentos dos 50\% melhores touros para os modelos HS (DEPhs $\geq 4,16 \mathrm{~kg})$ e $\mathrm{M}(\mathrm{DEPm} \geq 4,05 \mathrm{~kg})$.

Para melhor elucidar a relação entre os métodos, foram calculadas as correlações dispostas na Tabela 25.

Tabela 25 - Correlações simples e de rank das DEPs dos touros obtidas a partir dos diferentes modelos HS, HK e M, para ganho de peso da desmama ao sobreano

\begin{tabular}{lcccccc}
\hline \multicolumn{3}{c}{ Correlação de Pearson das DEPs } & \multicolumn{3}{c}{ Correlação de Spearman (Rank) } \\
\hline & HS & HK & M & HS & HK & M \\
\hline HS & 1,00 & 0,18 & 0,18 & 1,00 & 0,60 & 0,60 \\
HK & & 1,00 & 0,99 & & 1,00 & 0,99 \\
M & & & 1,00 & & & 1,00 \\
\hline
\end{tabular}

Assim como acontece com as demais características, as correlações de Pearson entre os métodos é menor quando se trata da comparação entre o método HS com os demais, permanecendo de alta magnitude quando se trata da correlação entre os métodos M e HK.

Quando se foca a correlação de rank entre os métodos, pode-se observar que a correlação existente entre HS e os outros dois métodos é de igual magnitude, porém, inferior à correlação existente entre os métodos HK e M. Isso torna evidente o fato de que não há grande diferença na ordem dos touros classificados pelos métodos $\mathrm{HK}$ e $\mathrm{M}$, o que não acontece com HS e M. 


\section{CONCLUSÕES}

Com base nos resultados obtidos, percebe-se que não há diferenças significativas quando são comparadas as DEPs calculadas a partir da média harmônica acrescida da média da característica (HK) e a partir da média aritmética (M). Os desvios-padrão e amplitudes são muito similares. A adição de uma constante à DEP, nesse caso representada pela média da característica, apenas desloca a média, reduzindo conseqüentemente o coeficiente de variação. Isso poderia ser importante para a visualização dos pecuaristas, uma vez que o valor observado no sumário estaria bem próximo da média da característica. Entretanto, os coeficientes de correlação de Pearson e de Spearman encontram-se muito próximos a unidade (valor máximo de correlação), sugerindo que não há mudanças na classificação dos touros quando esses são submetidos a essas duas metodologias, considerando-se as três características avaliadas.

Quando comparados os métodos que se utilizam apenas da média harmônica simples (HS) e média aritmética (M), há bastante discordância entre os touros classificados por uma ou outra metodologia, nas três características avaliadas. Para todas as características, inferindo-se as estatísticas realizadas, tanto a descritiva quanto de distribuição, tem-se a alusão de que o método $\mathrm{M}$ é mais favorável à menor variabilidade da progênie. Portanto, o uso da média harmônica sem a adição da média da característica estudada não é recomendado, pois apresenta valores muito variáveis, provavelmente em função do uso de valores muito próximos de zero.

Deste modo, independentemente da metodologia utilizada com a média harmônica, é aconselhável que a média aritmética continue sendo empregada como principal metodologia de estimação, até que mais estudos sejam realizados com a finalidade de se estudar a dispersão dos valores genéticos das progênies de touros submetidos às avaliações genéticas, com a intenção de uniformizar a progênie, uma vez que a média harmônica não foi capaz de corrigir a variabilidade das progênies. 


\section{IMPLICAÇÕES}

- A DEPhk calculada nesse estudo é diferente da DEPh proposta pela Gensys, embora existam semelhanças nos conceitos, pois ambas adicionam uma constante semelhante à média da característica;

- A adição de uma constante K às DEPs das progênies para se calcular a média harmônica é interessante e desejável, pois traz os valores da DEP para a escala da grandeza da variável, caso essa constante seja de valor próximo à média da característica. Porém, a grandeza de $\mathrm{K}$ pode alterar a classificação dos animais, especialmente quando se distancia da média.

- A diferença entre a DEPhk e a DEPm, de acordo com os conceitos utilizados neste trabalho, é praticamente inexistente.

- Um estudo sobre a influência das vacas pode ajudar na busca de progênies mais homogêneas. 


\section{REFERÊNCIAS BIBLIOGRÁFICAS}

ASSOCIAÇÃO BRASILEIRA DAS INDÚSTRIAS EXPORTADORAS DE CARNE. Estatísticas. Disponível em <http://www.abiec.com.br/estatisticas.asp>. Acesso em 25 de jul. 2007.

BEEF IMPROVEMENT FEDERATION. Proceedings. Disponível em <http://www.beefimprovement.org/proceedings.html>. Acesso em 02 de mar. 2007.

BERGMANN, J.A.G. Avaliação genética. In: PEREIRA, J.C.C. Melhoramento genético aplicado à produção animal. 4.ed. Belo Horizonte: FEPMVZ, 2004. p.554-577.

BIJMA, P.; MUIR, W.M.; VAN ARENDONK, J.A.M. Multilevel selection 1: quantitative genetics of inheritance and response to selection. Genetics, Bethesda v. 175, p.277-288, 2007.

BOLDMAN, K.G. et al. A manual for use of MTDFREML : a set of programs to obtain estimates of variance and covariance. Clay Center, NE: ARS - USDA, 1995. 113p.

BOLIGON, A.A. et al. Herdabilidades para ganho de peso da desmama ao sobreano e perímetro escrotal ao sobreano e tendências genética e fenotípica para ganho de peso da desmama ao sobreano em bovinos Nelore-Angus. Revista Brasileira de Zootecnia, Viçosa, v.35, n.4, p.1323-1328, 2006.

BOURDON, R.M.; BRINKS, J.S. Simulated efficiency of range beef production. I. Growth and milk production. Journal of Animal Science, v. 65, p. 943-955. 1987.

BROWN, M.A.; BROWN JR., A.H.; JACKSON, W.G.; MIESNER, J.R. Genotype x environment interactions in postweaning performance to yearling in Angus, Brahman, and reciprocal-cross calves Journal of Animal Science, v.71, p. 3273-3279, 1993.

BULLOCK, K.D.; BERTRAND, J.K., BENYSHEK, L.L. Genetic and environmental parameters for mature weight and other growth measures in Polled Hereford cattle. Journal of Animal Science, v.71, p.1737-1741, 1993.

CARDOSO, F.F., CARDELINNO, R.A.; CAMPOS, L.T. Parâmetros genéticos para escores de avaliação visual à desmama em bovinos da raça Santa Gertrudis. In: REUNIÃO ANUAL 
DA SOCIEDADE BRASILEIRA DE ZOOTECNIA, 35, 1998, Botucatu. Anais... Botucatu: SBZ, 1998. 1. CD-ROM.

CARVALHEIRO, R. et al. Estudo de simulação das relações entre a média aritmética, a média harmônica e o desvio-padrão do ganho médio diário de peso do. In: REUNIÃO ANUAL DA SOCIEDADE BRASILEIRA DE ZOOTECNIA, 2001, Piracicaba. Anais..., 2001. p. 626-627.

CARVALHO, T.B. Estudo da elasticidade-renda da demanda de carne bovina, suína e de frango no Brasil. 2007. 88 f. Dissertação (Mestrado) - Escola Superior de Agricultura Luiz de Queiroz, Universidade de São Paulo, Piracicaba, SP, 2007.

CINTRA, D.C. Interação genótipos-ambientes e parâmetros de adaptabilidade e estabilidade para características de crescimento em bovinos compostos no Brasil. 2007. 57f. Dissertação (Mestrado) - Faculdade de Zootecnia e Engenharia de Alimentos, Universidade de São Paulo, Pirassununga, SP, 2007.

COSTA NETO, P.L.O. Estatística. São Paulo: Edgard Blücher, 1977. 262p.

ELER, J.P. Utilização de modelos animais univariado e multivariado na avaliação genética de bovinos da raça Nelore. 1994. 112f. Tese (Livre-docência) - Faculdade de Zootecnia e Engenharia de Alimentos, Universidade de São Paulo, Pirassununga, 1994.

ELER, J.P. et al. Influência da interação touro $\mathrm{x}$ rebanho na estimação da correlação entre efeitos genéticos direto e materno em bovinos da raça Nelore. Revista Brasileira de Zootecnia, Viçosa, MG, v.29, n. 6, p.1642-1648, 2000.

ELER, J.P. Teorias e métodos em melhoramento genético animal, 2. ed., Pirassununga: FZEA/USP, 2001, 262 p. (Apostila).

EUCLIDES FILHO, K. Melhoramento genético animal no Brasil. Fundamentos, história e importância. 1 ed. Campo Grande: Embrapa, 1999, 63 p.

EVERLING, D.M., et al. Estimativas de herdabilidade e correlação genética para características de crescimento na fase de pré-desmama e medidas de perímetro escrotal ao sobreano em bovinos Angus-Nelore. Revista Brasileira de Zootecnia, Viçosa, v.30, n.6(supl.), p.2002-2008, 2001. 
FALCONER, D.S. Introduccion a la genetica cuantitativa. Agricultural Research Council's Unit of Animal Gentics University of Edinburgh. Compañia Editorial Continental. 1a Ed, 1970. 430p.

FERRAZ, J.B.S. Aplicação de modelos animais na avaliação de parâmetros populacionais de características reprodutivas e produtivas de coelhos das raças Califórnia e Nova Zelândia Branca. 1993. 123f. Tese (Livre-docência) - Faculdade de Zootecnia e engenharia de Alimentos, Universidade de São Paulo, Pirassununga, 1993.

FERREIRA, D.F. Estatística Básica. Lavras: UFLA, 2005. 664p.

FERREIRA, G.B.; MacNEIL, M.D.; Van VLECK, L.D. Variance components and breeding values for growth traits from different statistical models. Journal of Animal Science, v.77, p.2641-2650, 1999.

FRIES, L.A. Precocidade, precocidade e precocidade. Reunião da ABCZ. Uberaba. Anais..., 1996.

GARNERO, A.V. et al. Influência da incorporação de dados de progênies na classificação de touros da raça Nelore. Revista Brasileira de Zootecnia, Viçosa, v. 31, n.2, p. 918-923, 2002.

GUNSKI, R.J. et al. Estimativas de parâmetros genéticos para características incluídas em critérios de seleção em gado Nelore. Ciência Rural, Santa Maria, v.31, n.4, p. 603-607, 2001.

HARIKI, S. Média harmônica. In: MINISTÉRIO DA EDUCAÇÃO - SECRETARIA DE EDUCAÇÃO BÁSICA. Explorando o ensino da matemática. Brasília, 2004. Cap. 5, p.244251. Disponível em < mec.gov.br/seb/arquivos/pdf/EnsMed/expensmat_icap5.pdf >.

INSTITUTO BRASILERIO DE GEOGRAFIA E ESTATÍSTICA. Produção da pecuária municipal. Disponível em < http://www.ibge.gov.br/home/estatistica/economia/ppm/2005/comentarios.pdf > . Acesso em 5 de ago. 2007.

KEMPTHORNE, O. Statistical Models and Their Experimental Application. Journal of the American Statistical Association, v. 68, n. 341, p. 245-246. 1973. 
KINGHORN, B. Descrição e direcionamento dos objetivos do melhoramento. In.: VAN DER WERF, J.; RYAN, M. Melhoramento animal - Uso de novas metodologias. Piracicaba: FEALQ, 2006. Cap. 20, p.311-322.

KOOTS, K.R.; GIBSON, J.P. Effects of production and marketing circumstances on economic values for beef production traits. Canadian Journal of Animal Science, v. 78, p. 47-55. 1998.

KOOTS, K.R.; GIBSON, J.P. Realized sampling variances of estimates of genetic parameters and the difference between genetic and phenotypic correlations. Genetics, v. 143, p. 14091416, 2006.

LEE, J.W. et al. Parameter estimates for direct and maternal genetic effects on yearling, eighteen-month, and slaughter weights of Korean native cattle. Journal of Animal Science, v.78, p.1414-1421. 2000.

LEE, D.H.; BERTRAND, J.K. Investigation of genotype x country interactions for growth traits in beef cattle. Journal of Animal Science, v.80, n.2, p.330-337. 2002.

MERCADANTE, M. E. Z. et al. Direct and correlated responses to selection for yearling weight on reproductive performance of Nelore cows. Journal of Animal Science, v.81, p.376-384, 2003.

MERCADANTE, M.E.Z., LÔBO, R.B., OLIVEIRA, H.N. Estimativas de (Co)Variâncias entre características de reprodução e de crescimento em fêmeas de um rebanho Nelore. Revista Brasileira de Zootecnia, Viçosa, v.29, n.4, p.997-1004, 2000.

MEYER, K. Variance components due to direct and maternal effects for growth traits of Australian beef cattle. Livestock Production Science, v.31, n.3/4, p. 179-202, 1992.

MINISTÉRIO DA AGRICULTURA, PECUÁRIA E ABASTECIMENTO. Disponível em < http://www.agricultura.gov.br/ >. Acesso em 10 de jul. 2007.

MOURÃO, G.B. Estimação de efeitos genéticos aditivos diretos e maternos e não aditivos e, predição do desempenho de pesos, perímetro escrotal e musculosidade em uma população de bovinos de corte compostos (Bos taurus x Bos indicus). 2005. 110f. Tese (Doutorado) Faculdade de Zootecnia e Engenharia de Alimentos, Universidade de São Paulo, Pirassununga, 2005. 
MUNIZ, C.A.S.D. et al. Dois critérios de seleção na pré-desmama em bovinos da raça Gir. 2. Efeito na classificação dos animais. Revista Brasileira de Zootecnia, Viçosa, v.34, n.3, p.816-826, 2005.

NEWMAN, S.; MORIS, C.A.; BAKER, R.L.; NICOLL, G.B. Genetic improvement of beef cattle in New Zeland: Breeding objectives. Livestock Production Science, v.32, p. 111-130. 1992.

OLSON, K.M.; GARRICK, D.J.; ENNS, R.M. Predicting breeding values and accuracies from group in comparison to individual observations. Journal of Animal Science, v.84, p.8892. 2006.

ORTIZ-PEÑA, C.D.; CARVALHEIRO, R.; QUERIROZ, S.A.; FRIES, L.A. Comparison of selection criteria for pré-weaning growth traits of Nelore cattle. Livestock Production Science, v.86, p.163-167, 2004.

PANETO, J.C.C. et al. Estudo de características quantitativas de crescimento dos 120 aos 550 dias de idade em gado Nelore. Revista Brasileira de Zootecnia, v.31, n.2, p.668-674, 2002.

PAZ, C.C.P., ALBUQUERQUE, L.G., FRIES, L.A. Efeitos ambientais sobre o ganho de peso no período do nascimento ao desmame em bovinos da raça Nelore. Revista Brasileira de Zootecnia, v.28, n.1, p. 55-64, 1999.

PEREIRA, M.C. et al. Estimativas de parâmetros genéticos de características de crescimento em um rebanho Caracu selecionado para peso ao sobreano. Revista Brasileira de Zootecnia, Viçosa, v.35, n.4 (supl.), p.1669-1676, 2006.

PEREIRA, J.C.C. Melhoramento genético aplicado à produção animal. 4.ed. Belo Horizonte: FEPMVZ, 2004. 609 p.

PONZONI, R.W.; NEWMAN, S. Developing breeding objectives for Australian beef cattle production. Animal Production, v. 49, p. 35-47. 1989.

RESENDE, M.D.V.; PEREZ, J.R.H.R. Melhoramento animal: predição de valores genéticos pelo modelo animal - BLUP em bovinos de leite, bovinos de corte, ovinos e suínos. Archives of Veterinary Science, v. 4, p. 17-29, 1999. 
RIBEIRO, S. et al. Efeitos da interação genótipo x ambiente sobre a característica ganho de peso da desmama ao sobreano em animais da raça Nelore. In.: REUNIÃO ANUAL DA SOCIEDADE BRASILEIRA DE ZOOTECNIA, 42, 2005, Goiânia. Anais... Goiânia: SBZ, 2005. 1 CD-ROM.

SAS INSTITUTE. Statistical analysis systems user's guide. Version 8. Cary: SAS Institute Inc., 1999. 1464 p.

SERVIÇO DE INFORMAÇÃO DA CARNE. Breve histórico da produção de carne no Brasil. Disponível em <http://www.sic.org.br>. Acesso em 31 de jul. 2007.

SCHAEFFER, L.R.; SCHENKEL, F.S.; FRIES, L.A.. Selection bias on animal model evaluation. In.: 6TH WORLD CONGRESS ON GENETICS APPLIED TO LIVESTOCK PRODUCTION, v.25, Armidale, Proceedings... Armidale: 6WCGALP. p. 501-508. 1998.

SILVA, J.A.V. et al. Estimação de parâmetros genéticos para probabilidade de prenhez aos 14 meses e altura na garupa em bovinos da raça Nelore. Revista Brasileira de Zootecnia, Viçosa, v.32, n.5, p.1141-1146, 2003.

SIVANADIAN, B.; SMITH, C. The effect of adding further traits in index selection. Journal of Animal Science, v.75, p.2016-2023, 1997.

STREINER, D.L. Do you see what I mean? Indices of central tendency. Canadian Journal of Psychiatry, v.45, n.9, p. 833-836, 2000.

SUMÁRIO - Sumário de Touros Nelore CFM 2006. Agro-Pecuária CFM. - São José do Rio Preto: Agro-Pecuária - CFM, 2006. 56p.

SUMÁRIO - Sumário Paint Consolidado 2006. Lagoa da Serra Ltda - Sertãozinho: Lagoa da Serra, 2006. 48p.

TEIXEIRA, R. e ALBUQUERQUE, L. G. Efeitos ambientais que afetam o ganho de peso pré-desmama em animais Angus, Hereford, Nelore e mestiços Angus-Nelore e HerefordNelore. Revista Brasileira de Zootecnia, Viçosa, MG, vol. 32, n. 4, p. 887-890, 2003.

TRIOLA, M.F. Introdução à Estatística. LTC Editora. $7^{\mathrm{a}}$ ed. 1999. 410p.

UNITED SATATES DEPARTAMENT OF AGRICULTURE. Related topics: animal production. Disponível em: <http://www.fas.usda.gov/psdonline/psdHome.aspx> Acesso em: 
31 de julho de 2007.

VAN DER WERF, J. Tópicos primordiais em programas de melhoramento genético animal Uma visão geral. In.: KINGHORN, B.; VAN DER WERF, J.; RYAN, M. Melhoramento animal: uso de novas metodologias. Piracicaba: FEALQ, 2006. Cap.1, p.15-26.

VAN VLECK, L.D. Selection index and introduction to mixed model methods for genetic improvement of animals. Flórida: CRC Press, 1993. 481p. 